\title{
Pre-symptomatic transcriptome changes during cold storage of chilling sensitive and resistant peach cultivars to elucidate chilling injury mechanisms
}

Clara Pons Puig ${ }^{2+}$, Anurag Dagar ${ }^{1+}$, Cristina Marti Ibanez ${ }^{2}$, Vikram Singh ${ }^{1}$, Carlos H Crisosto ${ }^{3}$, Haya Friedman ${ }^{1}$, Susan Lurie ${ }^{1^{*}}$ and Antonio Granell ${ }^{2}$

\begin{abstract}
Background: Cold storage induces chilling injury (Cl) disorders in peach fruit (woolliness/mealiness, flesh browning and reddening/bleeding) manifested when ripened at shelf life. To gain insight into the mechanisms underlying $\mathrm{Cl}$, we analyzed the transcriptome of 'Oded' (high tolerant) and 'Hermoza' (relatively tolerant to woolliness, but sensitive to browning and bleeding) peach cultivars at pre-symptomatic stages. The expression profiles were compared and validated with two previously analyzed pools (high and low sensitive to woolliness) from the Pop-DG population. The four fruit types cover a wide range of sensitivity to $\mathrm{Cl}$. The four fruit types were also investigated with the ROSMETER that provides information on the specificity of the transcriptomic response to oxidative stress.

Results: We identified quantitative differences in a subset of core cold responsive genes that correlated with sensitivity or tolerance to $\mathrm{Cl}$ at harvest and during cold storage, and also subsets of genes correlating specifically with high sensitivity to woolliness and browning. Functional analysis indicated that elevated levels, at harvest and during cold storage, of genes related to antioxidant systems and the biosynthesis of metabolites with antioxidant activity correlates with tolerance. Consistent with these results, ROSMETER analysis revealed oxidative stress in 'Hermoza' and the progeny pools, but not in the cold resistant 'Oded'. By contrast, cold storage induced, in sensitivity to woolliness dependant manner, a gene expression program involving the biosynthesis of secondary cell wall and pectins. Furthermore, our results indicated that while ethylene is related to $\mathrm{Cl}$ tolerance, differential auxin subcellular accumulation and signaling may play a role in determining chilling sensitivity/tolerance. In addition, sugar partitioning and demand during cold storage may also play a role in the tolerance/sensitive mechanism. The analysis also indicates that vesicle trafficking, membrane dynamics and cytoskeleton organization could have a role in the tolerance/sensitive mechanism. In the case of browning, our results suggest that elevated acetaldehyde related genes together with the core cold responses may increase sensitivity to browning in shelf life.
\end{abstract}

Conclusions: Our data suggest that in sensitive fruit a cold response program is activated and regulated by auxin distribution and ethylene and these hormones have a role in sensitivity to $\mathrm{Cl}$ even before fruit are cold stored.

Keywords: Rosaceae, Microarray, Peach, Woolliness, Internal browning, Reddening

\footnotetext{
*Correspondence: slurie43@agri.gov.il

'Equal contributors

'Department of Postharvest Science of Fresh Produce, Agricultural Research

Organization, Volcani Center, P.O. Box 6, Bet Dagan 50250, Israel

Full list of author information is available at the end of the article
} 


\section{Background}

Cold storage is used to delay ripening and decay development of many commodities including peaches. However, low temperature storage of peaches also leads to development of chilling injury (CI) manifested as flesh browning (FB), reddening/bleeding (FBL) and woolliness/mealiness (WLT), which limits storage life. CI develops faster and more intensely when susceptible fruit are stored at temperatures between 2.2 and $7.6^{\circ} \mathrm{C}$ (killing temperature zone) than when stored at $0^{\circ} \mathrm{C}[1,2]$. These symptoms mainly develop during fruit ripening after cold storage, and the problem is not noticed until the fruit reaches customers [3].

WLT has been tied to improper cell wall disassembly $[1,2]$. In WLT fruit the most easily extractable cell wall pectins (soluble in water) are reduced in amount and are of higher molecular weight and viscosity than in ripened, juicy fruit $[4,5]$. The degree of methylesterification of pectin is also altered. Cell wall pectin participates in the wall in cell-to-cell adhesion, which is accomplished largely by calcium cross-linking between partially de-methylesterified homogalacturonan in the middle lamella [6]. It has been suggested that changes to pectin metabolism cause WLT either by cell fluids forming calcium-pectate gel complexes with high molecular weight pectin in the middle lamella [7], or that the decreased intercellular adhesion in WLT fruit reduces cell rupture during biting and chewing, preventing release of cellular contents [8].

The appearance of FB in the fruit flesh is thought to be related to tissue deterioration or senescence, which leads to changes in membrane permeability and the interaction between phenols and polyphenol oxidase (PO), which are generally found in separate compartments in the cell. Kader and Chordas [9] found that the browning potential of peaches depended on the total amount of phenolic compounds present in the fruit and the level of activity of PO.

FBL has not been studied in depth, but appears to have a large genetic component [1,2]. The symptoms are the dispersion of the anthocyanin pigment which is usually confined to an area next to the pit into the surrounding fruit flesh. Although this is classed as a chilling related disorder, it does not lead to off-flavors or changes in the fruit texture. Current breeding programs include the development of a red fleshed peach, since this will increase the nutritive value of the fruit [10].

Although each of these disorders will develop during cold storage of peaches they have different etiology, and may develop at the same or after different times of storage. Since the underlying molecular pathways of these disorders are different, unravelling and identifying the changes in gene expression leading to each symptom of chilling injury is complicated. What complicates matters more is that the symptoms of CI generally only develop during post-storage ripening; therefore fruits that appear healthy at the end of storage may develop one or more of the CI symptoms during post-storage warming.

Modern breeding of peaches started in the USA towards the end of the $19^{\text {th }}$ century and was based on a very limited number of genotypes [11]. Thus, because of this and because of their high degree of natural self-pollination, peach cultivars are known to have low genetic variability [12]. Although the genetic background of peaches is very limited, there are differences between cultivars in their resistance to prolonged cold storage and chilling injury. In an attempt to study the genetic basis for chilling injury, the commercial cultivar 'Dr. Davis' was crossed with 'Georgia Belle'. 'Dr. Davis' produces yellow, clingstone, non-melting flesh fruit mainly for the canning industry, while 'Georgia Belle' produces white, freestone, melting flesh fruit that are eaten fresh [13-15]. The progeny segregated in their sensitivity to cold storage and the sensitive peaches developed $80 \%$ woolliness and the tolerant peaches had no woolliness during ripening after 1 week's storage at $5^{\circ} \mathrm{C}[15,16]$.

The present study examines transcriptomic changes while the fruit are still in cold using the Chillpeach microarray (the limitations of this approach are discussed in [17]). In our study we examine harvested non-stored fruit and two time points of unripe stored fruit of two whitemelting-flesh cultivars, 'Oded' (Od, a cling-stone, early season peach) and 'Hermoza' (Hz; free-stone, mid-season peach), with different sensitivity towards $\mathrm{CI}$, in which symptoms of chilling injury (WLT, FB and FBL) are not apparent. Candidate genes associated to tolerance/sensitivity in these fruits were identified and expression of some genes was further validated by quantitative real-time PCR (qRT-PCR). We also validate the results and extend the Pons et al. [17] study by integrating $\mathrm{Od}$ and $\mathrm{Hz}$ data with expression data of pools of siblings from the Pop-DG population with contrasting sensitivity to WLT using the same sampling times (harvest, 1 and 2 weeks at $5^{\circ} \mathrm{C}$ ). This comparison has enabled us to find (i) genes that respond to cold similarly in all four peach fruit (core cold responses) (ii) but differ in their time/levels of expression and therefore may be directly related to the sensitivity/tolerance to cold and (iii) genes specific for different chilling injury symptoms and/or to the tolerance specific for each fruit cultivar. Furthermore, by using ROSMETER [18] we characterize in silico the Reactive Oxygen Species (ROS) signature (ROS types and their subcellular origins) of peach fruit during cold storage.

\section{Methods}

\section{Fruit material and post-harvest conditions}

The experiments were carried out with an early-season variety peach [Prunus persica (L.) Batsch 'Oded'] (Od) and a mid-season variety peach [Prunus persica (L.) Batsch 
'Hermoza'] (Hz) in 2009. Fruit of both cultivars were harvested, from a commercial orchard in Israel, at commercial maturity stage $(\mathrm{H})$, according to Kader \& Mitchel [19]. Fruit and physiological parameters at harvest are recorded in Table 1. Some fruit were allowed to ripen at shelf life during 3 days at $20^{\circ} \mathrm{C}$ (SL samples), while the rest were stored immediately at $5^{\circ} \mathrm{C}$. The fruit were removed from cold storage every week for up to three weeks (CS samples). Pooled mesocarp tissue from 5 fruit were flash frozen with liquid nitrogen and stored at $-80^{\circ} \mathrm{C}$ until further analysis. After each storage period, some fruit were ripened at $20^{\circ} \mathrm{C}$ for 3 days $(\mathrm{CS}+\mathrm{SL})$ for chilling injury and quality evaluation.

\section{Physiological parameters}

Physiological parameters were measured and averaged from 15 fruit at harvest, after cold storage and after subsequent shelf life ripening following the protocol described in Zhou et al. [5]. Firmness was measured on two pared sides of each fruit using a penetrometer fitted with an $8-\mathrm{mm}$ diameter plunger. A wedge-shaped slice (approx. $5 \mathrm{~g}$ ) was removed from each fruit in the replicates and the pooled sample was passed through an electric juicer (Moulinex, type 753, France) for the measurement of soluble solids content (SSC) and titratable acidity (TA). SSC was determined by a digital refractometer (Atago, Tokyo, Japan). The TA was determined by titration of 2 $\mathrm{mL}$ juice to $\mathrm{pH} 8.2$ with $0.1 \mathrm{~N} \mathrm{NaOH}$ and expressed as percentage of malic acid. Ethylene was determined by closing individual fruit in a $650 \mathrm{ml}$ jar for $1 \mathrm{~h}$, sampling the air in the container with a syringe and injecting into a gas chromatograph with a FID detector.

\section{Chilling injury evaluation}

Fruit were evaluated for different CI symptoms such as expressible of juice, hard textured fruit with no juice upon squeezing or woolly texture (WLT), flesh browning or pit cavity browning (FB) and internal reddening or flesh bleeding (FBL) after cold storage (CS) and after shelf life ripening during 3 days at $20^{\circ} \mathrm{C}(\mathrm{CS}+\mathrm{SL})$. Observations were made on 15 fruit at each observation time.

WLT was determined in both CS and CS + SL fruit as the amount of expressible juice as described in Dagar et al. [20]. Expressible juice was indicated as the percentage of free juice in total tissue [21]. WLT was also evaluated visually along with $\mathrm{FB}$ and $\mathrm{FBL}$ in $\mathrm{CS}+\mathrm{SL}$ fruit. Each fruit was cut into two halves through the suture plane. WLT was scored on a 5-grade scale, according to amount of juice released upon hand squeezing, as follows: 1 , very juicy; 1.5 , moderate juicy; 2 , less juicy; 2.5 , small amount of juice; and 3.0, almost no juice. FB and FBL were also scored according to a 5-grade scale, based on area covered as follows: 1 , no browning or reddening; 1.5 , affected area $<5 \% ; 2$, affected area $\geq 5 \%$ and $<25 \%$; 2.5 , affected area $\geq 25 \%$ and $<50 \%$; and 3.0, affected area $\geq$ $50 \%$. Results for WLT, FB and FBL were expressed as an index calculated as the percentage of the average of fruit with each $\mathrm{CI}$ level in the treatment.

\section{RNA extraction, microarray and data analyses}

For the microarray experiments, the mesocarp RNA for each genotype at harvest $(\mathrm{H})$, after cold storage for 1 week (CS1) and 2 weeks $(\mathrm{CS} 2)$ at $5^{\circ} \mathrm{C}$ were all converted into labeled cDNA and hybridized to the Chillpeach microarray [16]. All samples were compared using a dye-swap design against the common superpool reference used in Pons et al. [17]. Three replicates from each sample pool were hybridized in each case, one of them dye-swapped.

RNA purification, sample preparation and hybridization to Chillpeach microarray were performed as described in Ogundiwin et al. [16]. To generate raw data to be used for expression analysis Lowess M Log Ratio was used as expression value and patterns with more than $80 \%$ of missing values were filtered. In total, 3277 probes met the threshold for hybridization quality. Differentially expressed genes were identified from the raw dataset using Significance Analysis of Microarray software (SAM, [22]) as described in Pons et al. [17]. Statistical significance for global analysis was assessed with a false discovery rate (FDR) of $1 \%$, q-value $\leq 0.01$. A total of 3002 genes showed significance. Significant data were normalized to harvest expression values after removing 38 genes without data in $\mathrm{Hz}$ at harvest. A total of 2964 unigenes were used for further analyses. Statistical significances for direct comparisons between cold storage times were assessed with a FDR of $5 \%$, q-value $\leq 0.05$.

Principal component analysis and 2D-hierarchical cluster were performed on significant data using Acuity $^{\text {Tx }}$ (Axon instruments) as described in Pons et al. [17]. Functional enrichment is performed as described in Pons et al. [17] and results were visualized using, Matrix2png [23].

Table 1 Physiological parameters of 'Oded' and 'Hermoza' at harvest

\begin{tabular}{llllll}
\hline Cultivar & Weight $\mathbf{( g )}$ & Ethylene $\left(\boldsymbol{\mu} \mathbf{~ k g}^{-\mathbf{1}} \mathbf{h}^{-\mathbf{1}}\right)$ & SSC (\%) & TA (\%) & Firmness (Newton) \\
\hline Oded & $141 \pm 15.0 \mathrm{~b}$ & $0.69 \pm 0.53 \mathrm{a}$ & $11.9 \pm 0.90 \mathrm{~b}$ & $0.43 \pm 0.05 \mathrm{a}$ & $54.0 \pm 7.2 \mathrm{a}$ \\
Hermoza & $200 \pm 30.6 \mathrm{a}$ & $0.78 \pm 1.00 \mathrm{a}$ & $14.3 \pm 0.46 \mathrm{a}$ & $0.33 \pm 0.03 \mathrm{~b}$ & $62.8 \pm 11.2 \mathrm{a}$ \\
\hline
\end{tabular}

Different letters indicate significant differences at $\mathrm{P}<0.05$ (t-test). 
Comparison of the cold response of 'Oded' (Od), 'Hermoza' $(\mathrm{Hz})$ and pools of siblings from the Pop-DG population

In order to examine transcript abundance changes across different peach fruit differing in their sensitivity to chilling injury, and to compare these with the transcript abundance profiles generated from this study, transcriptome data from pools of siblings from the Pop-DG population at harvest and after one and two weeks of cold storage at $5^{\circ} \mathrm{C}$ were retrieved from Pons et al. [17]. For the comparative analysis genes with high quality values in the two experiments (see above) and differentially expressed between $\mathrm{Hz}$ and $\mathrm{Od}$ and between highly sensitive $(\mathrm{S})$ and less sensitive (LS) pools after one week of cold storage were selected. A dataset of 2207 genes was generated and used for the comparison. Clustering of total transcript accumulation within a specific treatment and fruit type was done using Euclidean distance and the $k$-means unsupervised clustering Acuity ${ }^{\text {tix }}$ (Axon instruments). For calculations the number of $\mathrm{k}$ clusters was set to 12 and the centroid for each cluster was randomly assigned. Spots with missing values were replaced with the average values across the arrays. Profiles with the same shape pattern were centered and scaled around the mean value across arrays. Transcripts were ordered in the clusters according to their contribution to principal component 1 of the PCA performed with the same dataset.

\section{Real-time quantitative reverse transcriptase-PCR analysis}

The transcript abundance of 10 selected genes (Additional file 1: Table S1) that were differentially expressed between Od and $\mathrm{Hz}$ were validated with quantitative reverse transcriptase polymerase chain reaction (qRT-PCR) analyses. Full length cDNA, primer design, optimum primer and cDNA concentrations, qRT-PCR reaction and quantification was performed as described in Dagar et al. and Pons et al. $[17,24]$. Primer sequences and amplicon lengths are given in Additional file 1: Table S1. Each biological sample was examined in duplicate with two to three technical replicates. The expression levels for the genes were calculated relative to the Initiation Factor eIF-4-Gamma (eIF-G) gene as described by Ogundiwin et al. [16], and the expression level of each analyzed gene transcript during cold storage in the $\mathrm{Od}$ and $\mathrm{Hz}$ samples was calculated relative to this harvest values.

\section{ROSMETER analysis}

The ROSMETER is a new bioinformatic tool (http://app. agri.gov.il/noa/ROS_desc.php), which can provide information on the specificity of ROS-related response for any data set [18]. The ROSMETER was fabricated by using data from Arabidopsis plants exposed to stresses occurring in different cellular compartments. A set of genes having Arabidopsis orthologs in Chillpeach [16] and differentially expressed at harvest and during cold storage in all four fruits studies was used for ROSMETER analysis. The obtained data set was arranged according to the instructions on the website and submitted for analysis. The output file represents correlation values between known oxidative stresses and the transcriptome of the two cultivars and the two pools of siblings at harvest and following cold storage of 1 and 2 weeks. Correlation values above 0.12 represent non-random correlations [18].

\section{Results}

Ripeness and chilling injury parameters of 'Oded' and 'Hermoza' peaches

The fruits of Od and $\mathrm{Hz}$ were slightly different at harvest. Ripening parameters and results of t-tests are summarized in Table 1. At harvest, Od peach fruit were 30\% smaller (by weight) than $\mathrm{Hz}$ peaches. Furthermore, $\mathrm{Hz}$ fruit were less acidic (0.33\% compared to $0.43 \%)$, and had higher soluble solids (14\% compared to $12 \%$ ). However, there were no significant differences in ethylene production or in firmness between fruit of the two cultivars. The ethylene levels in Od and $\mathrm{Hz}$ fruit were $0.69 \mu \mathrm{L} \mathrm{kg}^{-1} \mathrm{~h}^{-1}$ and $0.78 \mu \mathrm{L} \mathrm{kg}^{-1} \mathrm{~h}^{-1}$, respectively (Table 1). According to Kader \& Mitchell [19] both cultivars were harvested at similar commercial mature stage (M). However it is obvious that physiological differences exist between both cultivars at the mature commercial stage, related to their growing conditions, length of development and genetic background.

Although $\mathrm{Hz}$ peaches were firmer than Od peaches during storage (Figure 1A), these cultivars exhibited similar trends in firmness during $\mathrm{CS}$ at $5^{\circ} \mathrm{C}$. Fruit of both cultivars retained their firmness for the first two weeks of storage, and upon the third week in the cold began to soften (Figure 1A). The firmness levels of both cultivars during shelf life (SL) ripening following cold storage (CS), although much lower than during CS, was also similar; with Od reaching 7 to $9 \mathrm{~N}$, and $\mathrm{Hz}$ between 8 to $14 \mathrm{~N}$. These values were lower than the softening that occurred when the fruit were held for three days at $20^{\circ} \mathrm{C}$ without storage (Figure 1A).

Consistent with previous findings that Od fruit were resistant to CI in CS [21], expressible juice did not change during SL ripening after CS (remaining approximately 65\%) while $\mathrm{Hz}$ decreased to 27\% (Figure 1B) and no WLT was observed visually in Od fruit (Figure 1C). Further, there were no symptoms of FB or FBL in Od during ripening after CS for up to three weeks (Figure 1C). In contrast, $\mathrm{Hz}$ was sensitive to $\mathrm{CI}$, and developed FB and FBL during SL after 2 weeks of CS and all three CI symptoms after 3 weeks.

\section{Global transcriptome analysis}

The Chillpeach microarray [16] was used to analyze the transcriptomes of peaches from both cultivars at harvest 

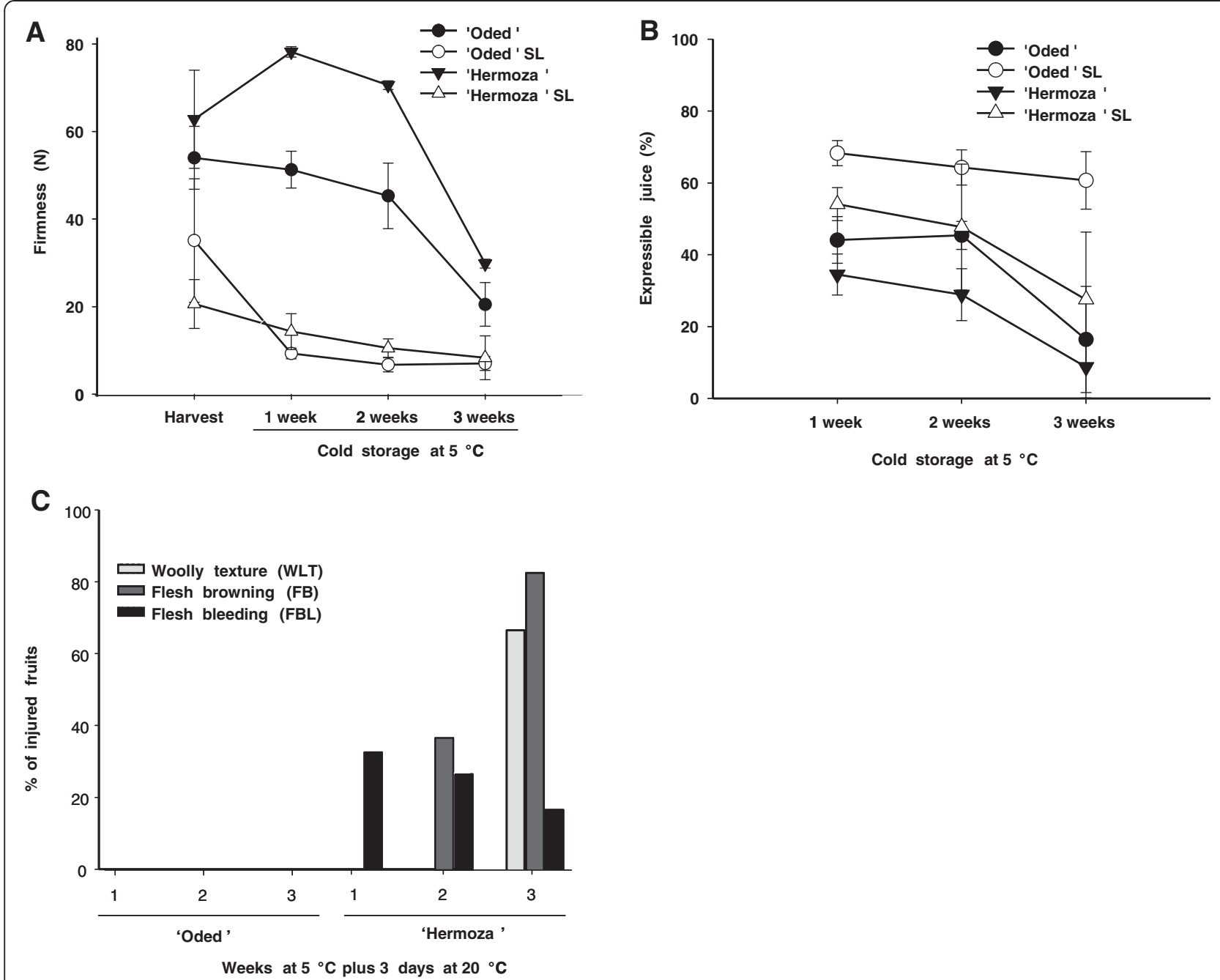

Figure 1 Comparison of chilling injury symptoms of 'Oded' and 'Hermoza'. A) Firmness of 'Oded' and 'Hermoza' peaches at harvest and after cold storage at $5^{\circ} \mathrm{C}$ (black colored symbols), and during ripening at $20^{\circ} \mathrm{C}$ (shelf life, open circles). Standard deviation is indicated. B) Expressible juice of 'Oded' and 'Hermoza' peaches at harvest and after cold storage at $5^{\circ} \mathrm{C}$ (black colored symbols), and during ripening at $20^{\circ} \mathrm{C}$ (shelf life, open symbols). C) Woolly texture (WLT), flesh browning (FB) and flesh bleeding (FBL) indices of 'Hermoza' peaches during shelf life after cold storage at $5^{\circ} \mathrm{C}$.

and after 1 and 2 weeks of storage. These stages were selected to investigate pre-symptomatic early events in the chilling response which may be associated to WLT, FBL and FB.

In total, 3277 probes met the threshold for hybridization quality (Additional file 2: Table S2). As a first approach to analyze the complexity of the gene expression dataset, a Principal Component Analysis (PCA) was performed on raw data. The three first components account for $80 \%$ of variance (Figure 2A, B). The results of the PCA plot showed consistency across replicated samples and treatments and, therefore, the experiment was considered reliable for further analysis. The $1^{\text {st }}$ component $(\mathrm{PC} 1$, $52.32 \%$ variance) clearly separated harvest from coldtreated samples (Figure $2 \mathrm{~A})$. The $2^{\text {nd }}$ component (PC2, $17.65 \%)$ separated cold stored samples of the tolerant cultivar Od from the sensitive $\mathrm{Hz}$. The $3^{\text {rd }}$ component (PC3) which contributed $10 \%$ of the difference in gene expression, separated the two cultivars at harvest (Figure 2B), which indicates that most of differences in the transcriptome induced by cold are due to differences in the sensitivity to develop injury rather than to differences at harvest. However, PC3 shows that genes differentially expressed at harvest reach similar expression values after being cold stored 1 and 2 weeks in Od and after 1 week in $\mathrm{Hz}$, but not $\mathrm{Hz}-\mathrm{CS} 2$ fruit, which were projected separately from the other cold stored samples. This indicates that genes differentially expressed at harvest could be involved in the eventual injury these fruit suffered when shelf ripened after two weeks in the cold (i.e. FB) but not to the phenotypical differences observed by just one week (i.e. FBL). 


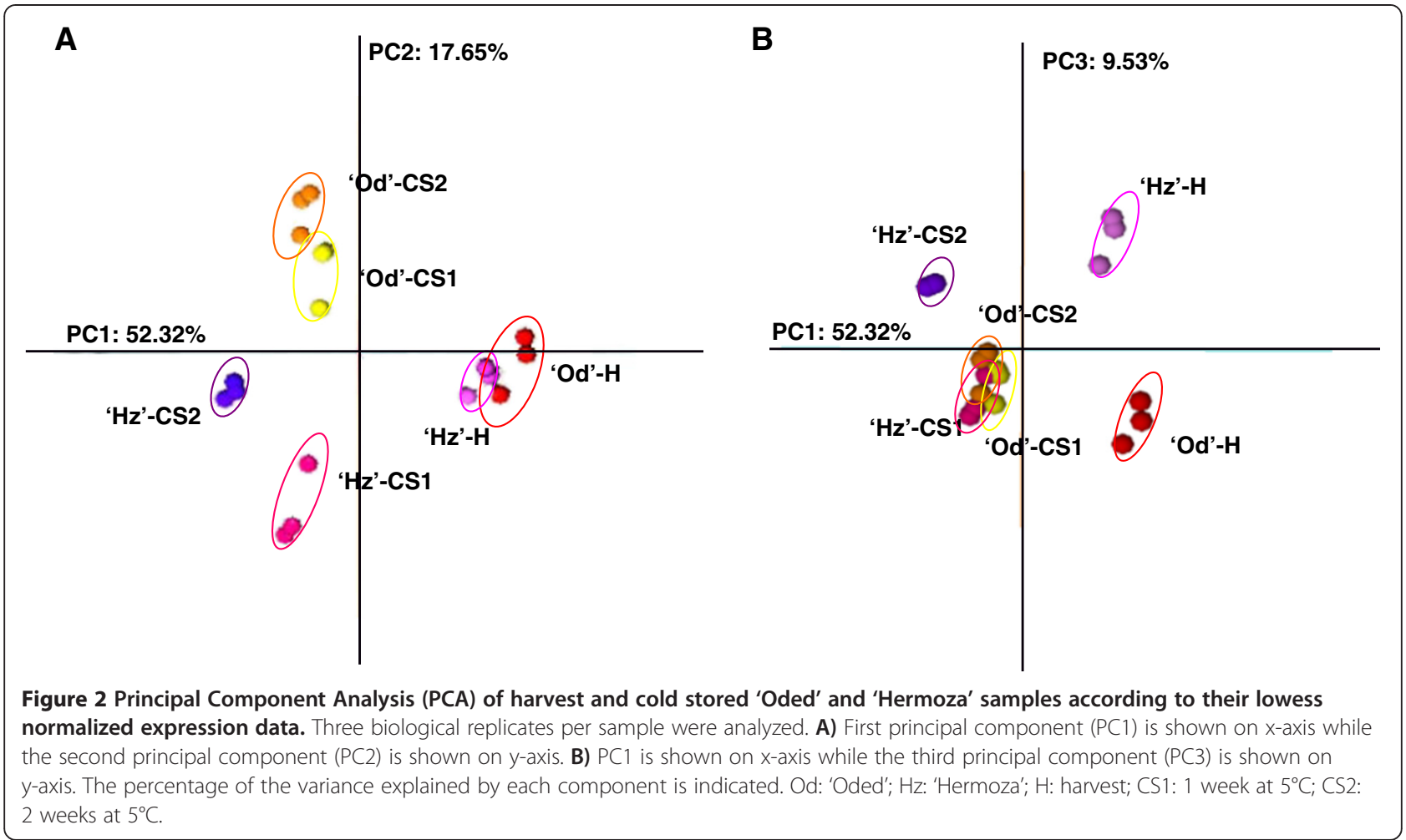

Differences in the transcriptome of 'Oded' and 'Hermoza' fruits at harvest and during cold storage

A direct comparison between $\mathrm{Od}$ and $\mathrm{Hz}$ peaches at harvest and at the different cold storage periods (CS1 and CS2) was carried out in order to identify genes differentially expressed in between the two cultivars and thus, eventually, to discover genes involved in chilling injury resistance/sensitivity at pre-symptomatic stage. As shown in Figure 3A the number of differentially expressed genes between the two cultivars was higher following cold storage ( 1 and 2 weeks) than at harvest, thus confirming PCA results.

A total of 735 genes were differentially expressed at harvest, and out of these 344 and 393 genes were upand down-regulated, respectively, in Od compared with $\mathrm{Hz}$ at harvest (Figure 3A; Additional file 3: Table S3). As shown in Figure $3 \mathrm{~B}$, the genes with higher expression in Od at harvest were functionally enriched in RNA translation and protein assembly, cytoskeleton organization and biogenesis, secondary metabolism, glycolysis and organelle division and differentiation. Genes under-represented (i.e., overexpressed in the sensitive cultivar $\mathrm{Hz}$ ) were enriched in antioxidant system, signal transduction, post-translational protein modification and unknown function (Figure 3C). Approximately 90\% of the genes differentially expressed at harvest have altered expression during cold storage (Figure 3A). This suggests that they have to do with the differential chilling response in both cultivars (as we showed in PCA, Figure 2). However, some of them belonging to functional categories such as cell wall, glycolysis, tricarboxylic acid cycle (TCA) and other carbohydrate metabolism, and may also account for the physiological differences observed between Od and $\mathrm{Hz}$ at harvest (firmness, soluble solid content, acidity; see Table 1; Additional file 3: Table S3). By one week of CS, 1990 genes were differentially expressed (Figure 3A).

Functional enrichment indicated that RNA translation and protein assembly was higher in $\mathrm{Od}$ than in $\mathrm{Hz}$, both at harvest and during 1 and 2 weeks of cold storage (Figure 3B). Out of 42 genes in this functional class over-represented in $\mathrm{Od}$ at harvest, 21 genes were also higher expressed in Od at one week of cold and 12 genes by two weeks. Moreover, 61 genes also showed high expression levels in Od by 1 and 2 weeks of cold storage and twenty genes were common in all three time points (Additional file 3: Table S3). This suggests that enhanced protein synthesis at harvest and during cold is critical for tolerance development. Secondary metabolism and glycolysis enriched genes were highly expressed in Od both at harvest and after 2 weeks of cold storage (Figure 3B). This overlap indicates that differences at harvest may account for the differences observed at 2 weeks of CS, as suggested the PCA (Figure 2). Genes of the signal transduction and transport functional categories were enriched in the sensitive cultivar $\mathrm{Hz}$ at harvest and also after 1 week of CS (Figure 3C), thus suggesting that they may be 


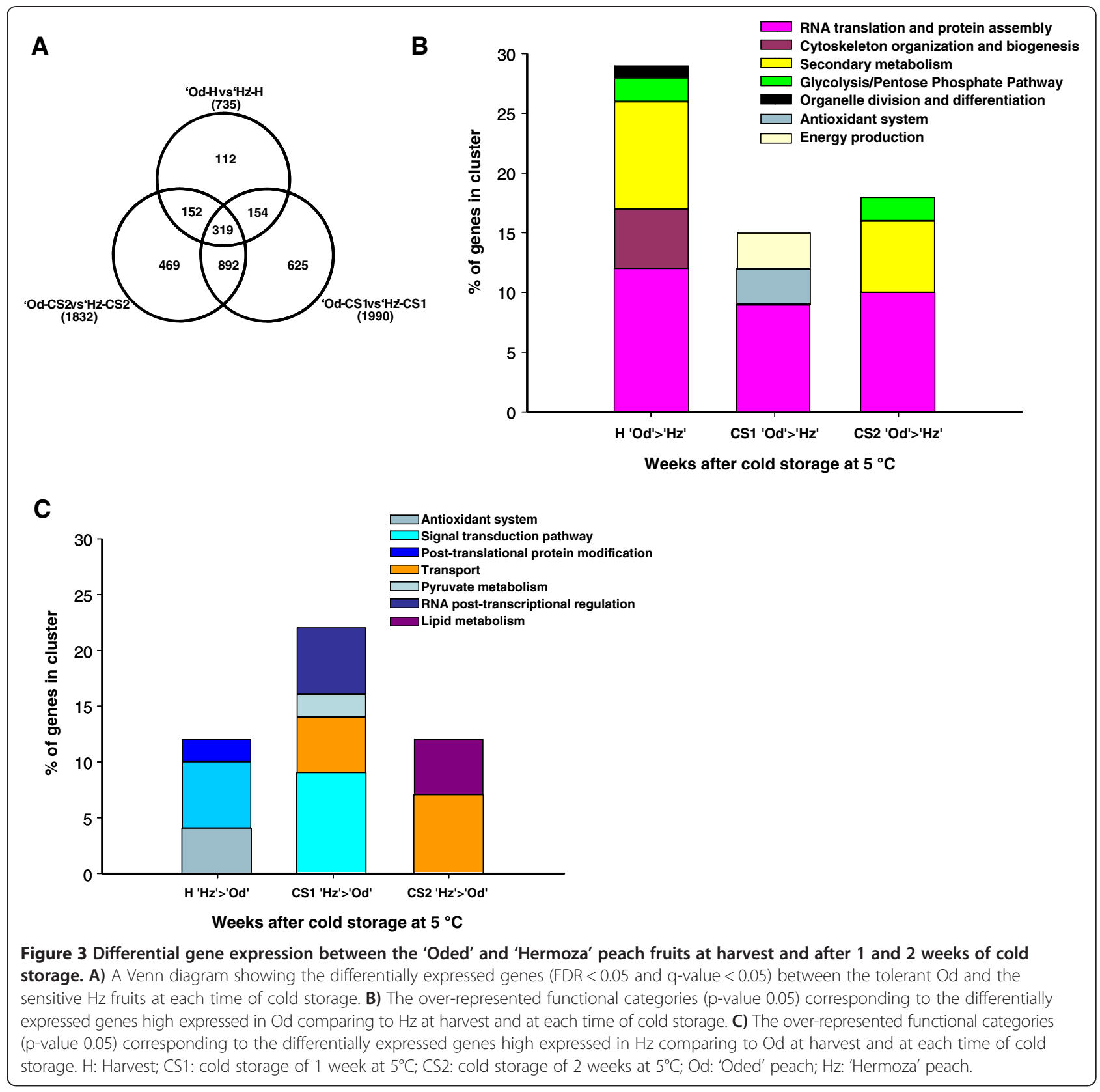

related to the sensitivity to cold storage. The functional category antioxidant systems was enriched in both cultivars at different time points. Fifteen antioxidant related genes were more highly expressed in $\mathrm{Hz}$ at harvest (15 genes) and 30 were over-represented in CS1 of Od peaches (Figure 3B and C). Out of the 15 genes encoding for antioxidant activities, 11 were high expressed in Od peaches at one week. This suggests that high levels of antioxidants at harvest are not directly related to the tolerance to cold storage, rather it appears that high levels of antioxidants during cold storage contribute to the tolerance. In addition, only four genes encoding for antioxidant activities were highly expressed in $\mathrm{Hz}$ at harvest and, as is the case of the orthologs of catalase 2 (CAT2) and thioredoxin (TRXH2), also during cold storage (Additional file 3: Table S3), suggesting that they are related to the sensitivity to cold.

\section{Kinetics of the cold response in 'Oded' and 'Hermoza'}

To investigate chilling-induced alterations in the gene expression profiles of the two cultivars in this study, differentially expressed genes were assessed with a false discovery rate (FDR) of $1 \%$, q-value $\leq 0.01$ based on three replicates. We found 2964 genes differentially regulated at least for one condition (samples $\mathrm{H}$ and CS samples) in either of genotypes. To distinguish whether transcripts are 
differentially affected by cold and analyze kinetics while avoiding the effect of harvest differences, expression data was normalized to harvest values. Differentially expressed transcripts were grouped according to shared cold expression patterns by Hierarchical Cluster Analysis (HCA) (Figure 4A; Additional file 4: Figure S1) and further characterized by functional enrichment (Figure 4B). In order to reflect the expression levels of genes at harvest, the average expression value of all genes in a cluster and the percentage of genes with higher expression levels in each cultivar (from the direct comparison; Figure 3) and each cluster were plotted in the graphic together with the cold expression profile. Only when the percentage of genes more highly expressed in a cultivar exceeded $20 \%$ of the genes in a cluster, was their contribution considered significant. The HCA resulted in 13 clusters (Figure 4A). Based on their expression during cold storage, these genes can be classified into several groups as follows.

The largest group (A) comprises cold responsive genes irrespective of sensitivity to cold storage. These included 685 genes (cluster 1, Figure 4A) up regulated by cold storage and enriched in RNA transcription regulation (Figure 4B) and 767 genes cold down-regulated (in clusters 12 and 13; Figure 4A) enriched in cytoskeleton organization, organelle division, photorespiratory pathway (cluster 12; Figure 4B) and antioxidant system, homeostasis, and sulfur metabolism (cluster 13; Figure 4B). This indicates that cold storage in both peach cultivars involves the activation of several transcriptional cascades and an extensive down-regulation of housekeeping and metabolic functions. Most of genes in clusters 1 and 13 do not show statistical differences in expression at harvest, while $41 \%$ of genes in cluster 12 were highly expressed in Od at harvest (Figure 4A). This suggests that, although the effect of cold on genes in cluster 12 is down-regulation, high levels at harvest can contribute to withstanding cold storage.

The second group (B) includes 538 genes comprised of clusters 2, 3 and 4 that most likely contains genes upregulated during cold storage in the sensitive cultivar $\mathrm{Hz}$ while down-regulated in the tolerant Od (Figure 4A), suggesting a possible relation to chilling sensitivity. Genes in clusters 2 and 3 were enriched in genes related

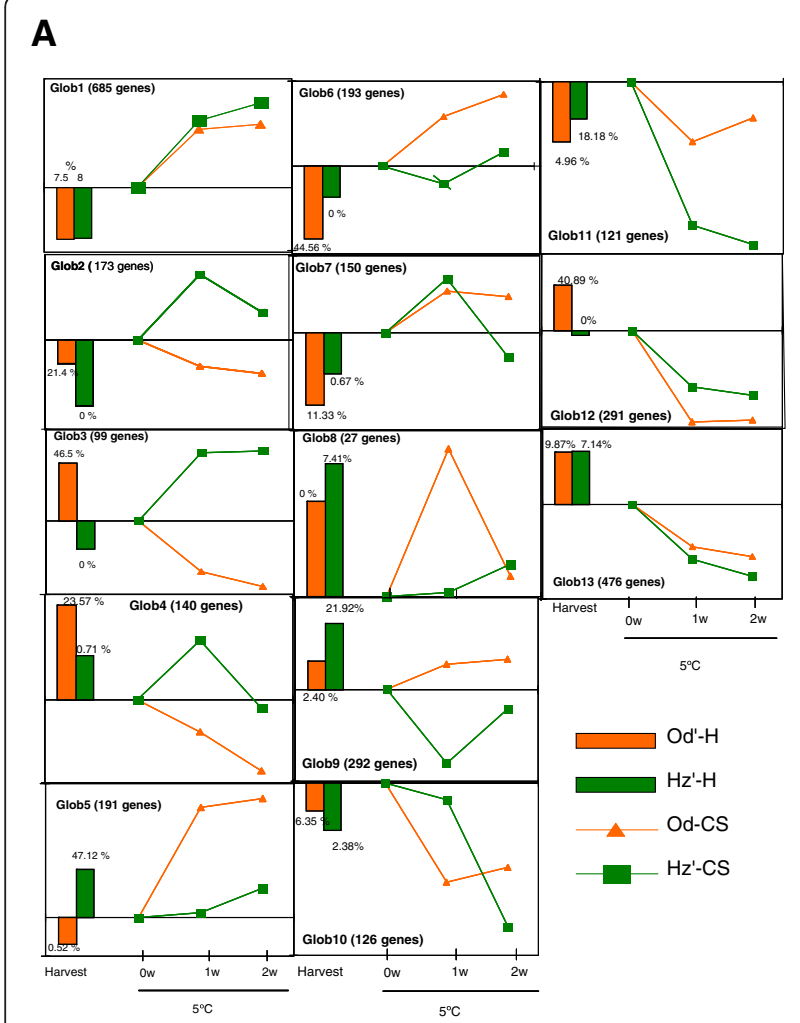

\section{B}

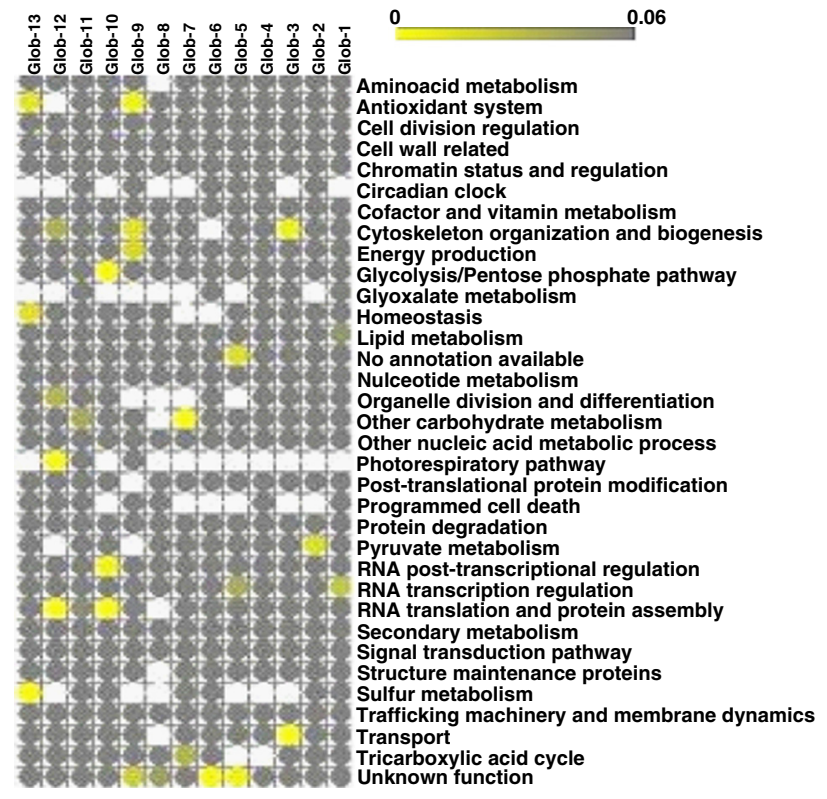

Figure 4 Kinetics of cold responsive genes in 'Oded' and 'Hermoza' fruits during cold storage and harvest values. A) Average gene expression pattern relative to harvest of genes in each of the 13 clusters generated by unsupervised two-dimensional hierarchical clustering (Additional 4: Figure S1). Od and $\mathrm{Hz}$ harvest values (bars) represents the average fold change of all genes within a cluster with respect to the reference pool. The percentage of genes high expressed at harvest in each cultivar and cluster is indicated together with expression bars. The number of genes in each cluster is indicated between brackets. B) The functional categories overrepresented in each cluster are shown as a heatmap obtained with matrix2png. Enriched functional categories with Fisher test $\mathrm{p}$-values $<0.05$ are colored in grades of yellow. Harvest; CS1: cold storage of 1 week at $5^{\circ} \mathrm{C}$; CS2: cold storage of 2 weeks at $5^{\circ} \mathrm{C}$; Od: 'Oded' peach; Hz: 'Hermoza' peach. 
to pyruvate metabolism, cytoskeleton organization and transport (Figure 4B). Genes in cluster 4, which was transiently up-regulated in $\mathrm{Hz}$ (Figure 4A) did not show any enrichment. It is noteworthy that $20 \%$ of the genes in clusters 2, 3 and 4 clusters were expressed at higher levels in Od cultivar at harvest (Figure 4A), especially genes in cluster 3, where genes with higher expression levels in Od-H account for $46.5 \%$ of genes, suggesting that they may be part of a constitutive tolerance mechanism. However, the observation that these genes were cold-induced in the sensitive cultivar $\mathrm{Hz}$ indicated that they could be required for setting up the initial response to cold, but do not enable the fruit to stand long term cold periods.

The third group $(C)$ included 797 genes included in clusters 5, 6, 9 and 11 that during cold storage were expressed at higher levels in Od compared to $\mathrm{Hz}$ (Figure 4A), and thus may be related with to $\mathrm{CI}$ resistance. Clusters 5, 6 and 9 comprised genes up-regulated in Od during CS, but unaffected or even decreased in $\mathrm{Hz}$ (Figure 4A). Genes in clusters 5 and 6 were enriched in genes without annotation or with unknown function; however class 9 was enriched with genes related to antioxidant system, cytoskeleton organization, energy production and genes of unknown function (Figure 4B). More than 20\% of genes in these three clusters were expressed at higher levels in the sensitive cultivar before cold stress, but during cold storage most of them reach expression values higher in Od than in $\mathrm{Hz}$ (Figure 4A). This suggests that high levels of these genes may contribute to the tolerance to cold storage and that the ability to up-regulate these genes during cold was related to low levels at harvest. The genes of cluster 11, enriched in other carbohydrate metabolism (Figure 4B), were down-regulated during cold storage in both cultivars; however the expression levels in Od were always higher than in $\mathrm{Hz}$ (Figure 4A). No significant differences were observed at harvest. Interestingly, this cluster (Additional file 3: Table S3) contained the orthologs of CBF1 (C-repeat/DRE Binding Factor 1) and CAMTA2 (Calmodulin Binding Transcription Activator 2), two transcription factors playing important roles during cold acclimation $[25,26]$, thus confirming the possible role of the genes in group $C$ in chilling injury tolerance.

A fourth group (D) was formed by clusters 7,8 and 10. The genes in these clusters did not show in general differences at harvest, but had the particularity of being transiently up-regulated or maintained at harvest expression level in one of the cultivars (Figure 4A). The genes in cluster 7, enriched in other carbohydrate metabolism and TCA genes (Figure 4B), were up-regulated to similar rates in both cultivars, but repressed in the sensitive cultivar after two weeks, when browning started to develop when fruit were shelf ripened. This suggests that down-regulation of these genes might be related to the development of injury at a pre-symptomatic stage. The genes in cluster 8, enriched in genes with unknown function, did not respond to cold in $\mathrm{Hz}$ but transiently upregulated in Od, suggesting a possible regulatory role of these genes. Genes in cluster 10 (Figure 4A) which was enriched in glycolysis, RNA posttranslational regulation, and RNA translation and protein assembly (Figure 3B), did not respond to cold in $\mathrm{Hz}$ during the first week while being down-regulated in Od from this time (Figure 4A). This suggests that the response to cold of these genes was delayed in the sensitive cultivar $\mathrm{Hz}$ which may be counterproductive to withstanding the cold storage.

\section{Validation of $\mathrm{Hz}$ and $\mathrm{Od}$ microarray results}

In order to validate the microarray results, we performed qRT-PCR on ten peach genes selected from the list of genes differentially expressed between $\mathrm{Od}$ and $\mathrm{Hz}$ fruits using gene specific primers (Additional file 1: Table S1). The tested genes were chosen from different processes including cell wall, RNA transcription regulation, secondary metabolism, signal transduction pathway and trafficking machinery and membrane dynamics (Additional file 5: Table S4). A total of 60 comparisons were made, as the expression of each gene was monitored at three time points ( $\mathrm{H}, \mathrm{CS} 1$ and $\mathrm{CS} 2)$ in $\mathrm{Od}$ and $\mathrm{Hz}$, using the same samples used for microarray analyses. The overall correlation observed between microarray and qRT-PCR analysis was $\mathrm{R}=$ 0.88 (Figure 5A). In addition, we also evaluated the agreement between each gene's expression profiles determined by qRT-PCR and microarrays using Pearson correlation coefficient (Additional file 5: Table S4). The qRT-PCR data correlate well (range $\mathrm{R}=0.8-1$, six genes) or are consistent (range $\mathrm{R}=0.5-0.8$, four genes) with the patterns of expression revealed by microarray analysis, and four examples (Figure 5B) include those for Thaumatin-like protein 1 (PPN003H07), aminocyclopropane-1-carboxylic acid (ACC) synthase (ACS1; PPN004H06), ACC oxidase (ACO; PP1005G06) and the ortholog of the transcription factor indoleacetic acid-induced protein 27 (IAA27/PAP2; PPN057F01), reported as being associated to woolliness tolerance at a pre-symptomatic stage $[17,20,2728]$. These results confirm the general validity and robustness of the microarray data we present here.

Another source of validation comes from the microarraybased genome-wide analysis of pools from Pop-DG population with contrasting WLT sensitivity in response to cold storage [17]. The similarity between of Pons et al. [17] data and those presented here for $\mathrm{Od}$ and $\mathrm{Hz}$ (same developmental stage, treatments as well same expression platform and reference pool for hybridization), allow direct comparison of expression profiles and values between studies.

The pools of the Pop-DG population are less tolerant to WLT than Hz. The most sensitive pool (high sensitive, S) was already mealy/woolly after one week of cold 


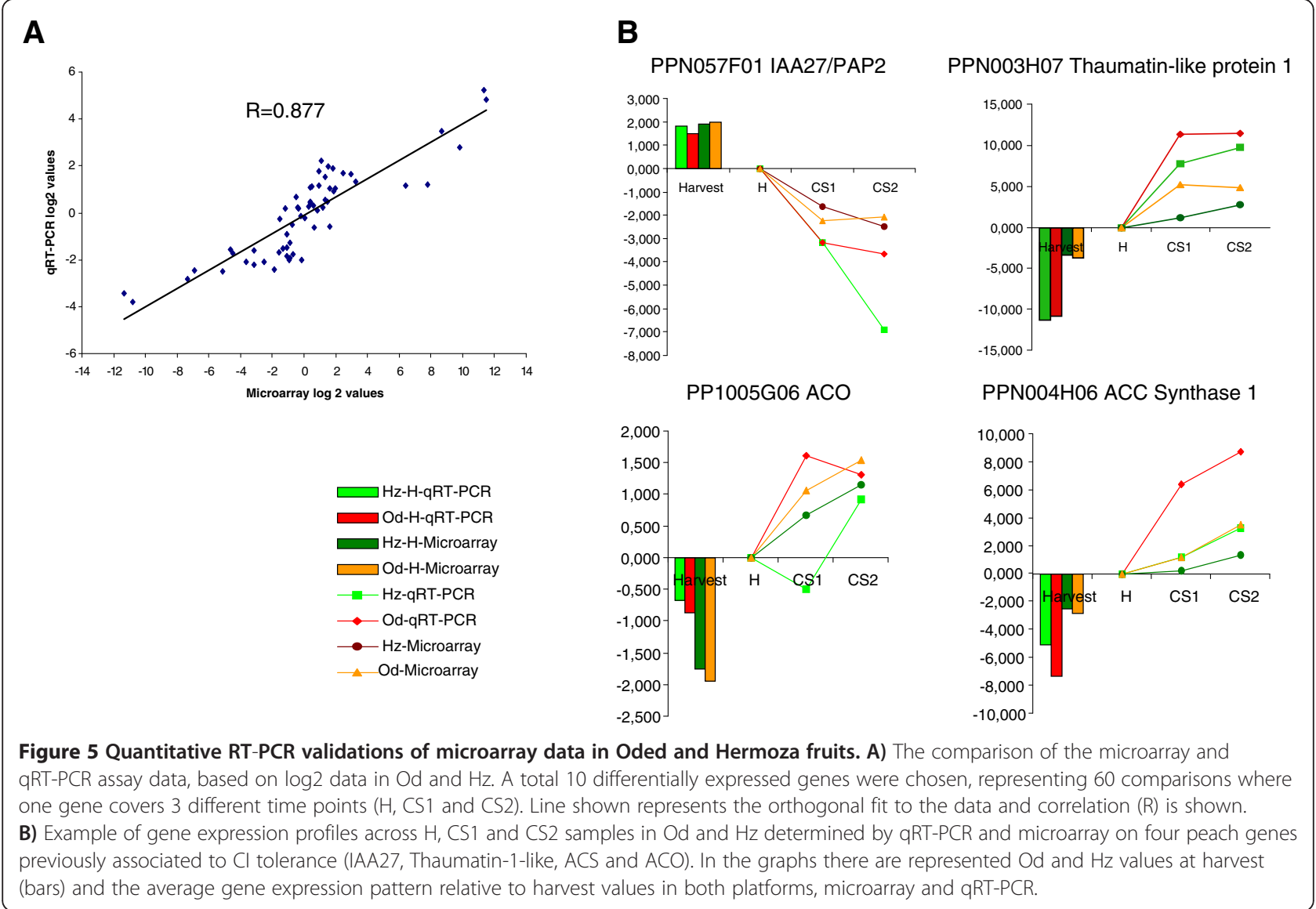

storage at $5^{\circ} \mathrm{C}$ plus shelf life ripening, while the relative tolerant (low sensitive, LS) was damaged after two weeks of cold storage [17]. However, while $\mathrm{Hz}$ was more resistant to WLT (fruit showed WLT symptoms after 3 weeks in cold) the siblings from Pop-DG population were tolerant to FBL and FB [17], which developed in $\mathrm{Hz}$ during ripening after two weeks of storage. However if tolerance/sensitive mechanisms are conserved, we expect that genes high expressed in the tolerant Od by compared to $\mathrm{Hz}$, were high expressed in the LS pool compared to the $\mathrm{S}$ pool.

We have compiled a dataset of 2207 genes (Additional file 6: Table S5) integrating expression values for cold responsive genes, differentially expressed at one week of cold storage, when the largest number of differentially expressed was found among all fruit. Then we determined the percentage of differentially expressed genes identified in each study (Od vs $\mathrm{Hz}$ and LS vs $\mathrm{S}$ pools) that shared the expression patterns. The comparison between both experiments resulted in more than $55 \%$ of the genes showing consistent patterns of expression (Additional file 6: Table S5). These 'consistent genes' corresponded to genes highly expressed in the LS pool that also showed higher expression levels in $\mathrm{Od}$ than in $\mathrm{Hz}$, while genes with higher expression in $\mathrm{S}$ pool than in the LS pool showed higher expression levels in $\mathrm{Hz}$. The rest of cold responsive genes were only differentially expressed in one of the experiments (20-30\%) or showed an opposite pattern $(<10 \%)$. These observed differences may indicate differences in the response to cold due to cultivar. Nonetheless, considering that $55 \%$ of genes had similar transcript profiles across samples and the low proportion of genes behaving in opposite direction, this comparative transcriptomic approach provides a valuable indication of a set of candidate genes that can be related to tolerance/sensitivity to $\mathrm{CI}$ in peach.

\section{Comparison of the transcriptomes of 'Oded' and 'Hermoza'} with Pop-DG siblings with contrasting sensitivity to WLT

To identify changes in gene expression that could be causally related to the tolerance/sensitivity to cold storage in peach fruit, we analyzed together the transcriptomes of $\mathrm{Od}, \mathrm{Hz}$ and the $\mathrm{LS}$ and $\mathrm{S}$ pools by k-means clustering (Figure 6A; Additional file 6: Table S5). We reasoned that changes in gene expression common to all peach fruit are more likely to be part of core cold responses while differences may provide genes for the specific response of each fruit genotype to cold storage, and which may or may not be involved in tolerance. According to this, genes in clusters k-means 2, 5 and 9 (Figure 6A) 

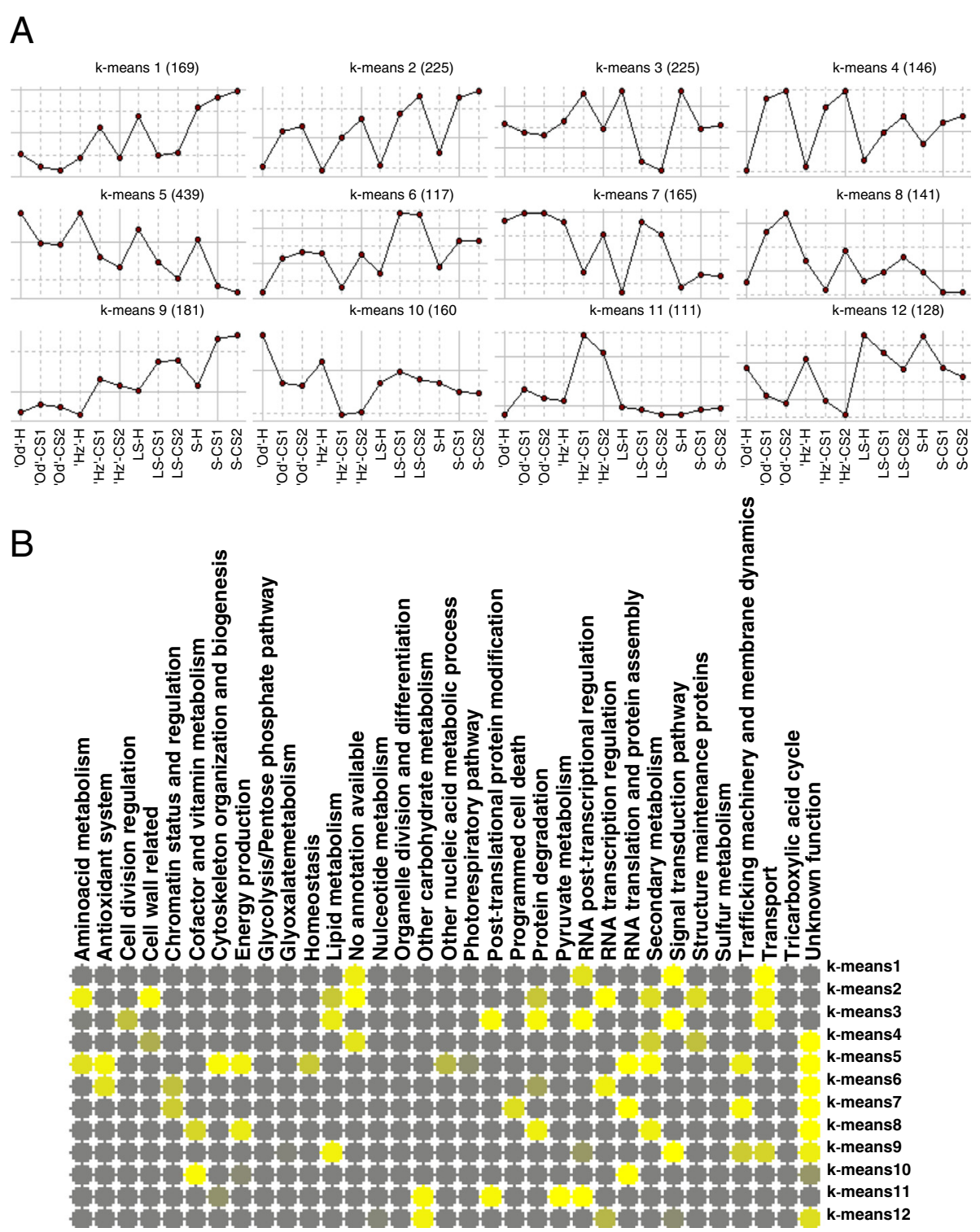

Figure 6 Integrative analysis the transcriptomes of 'Oded', 'Hermoza' and two pools of siblings from the Pop-DG population that cover a range of cold susceptibilities. A) K-means clustering results of a set of 2207 genes with a 12-cluster limit. B) The functional categories overrepresented in each cluster are shown as a heatmap obtained with matrix2png. Enriched functional categories with Fisher test $p$-values $<0.05$ are colored in grades of yellow. Tolerance-sensitivity range: $\mathrm{Od}>\mathrm{Hz}>\mathrm{LS}>\mathrm{S}$. H: Harvest; CS1: cold storage of 1 week at $5^{\circ} \mathrm{C}$; CS2: cold storage of 2 weeks at 5C; Od: 'Oded' peach; Hz: 'Hermoza' peach; LS: low sensitive Pop-DG pool; S: high sensitive Pop-DG pool.

were classified as part of the core cold response, but differ in their time/levels of expression and therefore are related to the degree of sensitivity/tolerance to cold. Given the common CI response that these fruit had was WLT; probably most of them were related to this disorder. Genes in cluster 2 and 9 were up-regulated by cold in a manner similar to their propensity to develop WLT (S > $\mathrm{LS}>\mathrm{Hz}>\mathrm{Od}$; Figure 6A). The main difference between these clusters was that in k-means 9 the expression level at harvest correlated to sensitivity. Genes in cluster kmeans 2 were enriched in RNA transcription regulation, cell wall, transport, amino acid metabolism, secondary metabolism, structure maintenance proteins, lipid metabolism, protein degradation and genes without any annotation (Figure 6B). Genes in cluster k-means 9 were enriched in signal transduction pathway, lipid metabolism, unknown function, transport, trafficking machinery and membrane dynamics, RNA post-transcriptional regulation (Figure 6B). In addition to up regulated genes, core cold responses also included down-regulated genes (cluster k-means 5). The genes in cluster k-means 5, enriched in RNA translation and protein assembly, 
secondary metabolism, cytoskeleton organization and biogenesis, antioxidant system, energy production, trafficking machinery and membrane dynamics, aminoacid metabolism, homeostasis, other nucleic acid metabolic process and genes with unknown function, were downregulated by cold inversely to CI sensitivity (Figure 6B). Therefore, high levels of these genes contribute to the tolerance to cold storage.

The other clusters with interesting patterns included clusters k-means 1,8 and 11 . The genes in k-means 1 , enriched in signal transduction pathway, transport, RNA post-transcriptional regulation and genes without any annotation available (Figure 6B) may be related to the higher sensitivity to WLT of the fruit in S pool. The genes in k-means 1 have expression levels at harvest that correlated to sensitivity degree and were up-regulated by cold in the $\mathrm{S}$ pool, but did not change in Od or were down regulated in $\mathrm{Hz}$ and in the $\mathrm{LS}$ pool (Figure 6B). The genes in the cluster k-means 11, enriched in pyruvate metabolism, RNA post-transcriptional regulation, posttranslational protein modification, other carbohydrate metabolism and cytoskeleton organization and biogenesis (Figure 6B), were highly up-regulated by cold in $\mathrm{Hz}$ but unaffected in the three other fruits (Figure 6A). These genes are candidates regarding the sensitivity of $\mathrm{Hz}$ fruit to FB and FBL. The genes in cluster k-means 8 may be associated with the high tolerance of Od fruit to CI. They were up-regulated in Od by cold storage, but unchanged in the other fruits in comparison to Od (Figure 6A), and were enriched in protein degradation, secondary metabolism, energy production, cofactor and vitamin metabolism and genes with unknown function (Figure 6B).

In addition, and in order give more robustness to this comparison, we searched for the 50 genes that in our previous work [17] were validated in the contrasting pools and in 15 individual lines from the same population differing in the woolliness sensitivity by mediumthroughput qRT-PCR. Forty of these genes were found in the comparison between $\mathrm{Hz}$ and $\mathrm{Od}$ and the pools (Additional file 7: Table S6). Out of them 34 were also confirmed in the 15 individual lines from the same population and 20 corresponded to the most relevant clusters (k-means 1, 2, 5 and 9). Overall, there was good agreement between the cluster analysis (Figure 6A) and the results for the validation in the individual lines. Out of the genes in cluster k-means 1, 2 and 9 (up-regulated by cold in a manner similar to their propensity to develop WLT), 15 out of 16 genes were found correlated to sensitivity in the individual Pop-DG lines. Similarly, five genes found in the cluster k-means 5 (down-regulated by cold in a manner similar to their propensity to develop WLT), were found associated to the high degree of tolerance of the individual lines. Further, genes such as ACS1 (PPN004H06), IAA27/PAP2 (PPN057F01), glycosyltransferase (PP1004E08) and an unknown extracellular protein (PP1001A01) validated in the comparison between $\mathrm{Od}$ and $\mathrm{Hz}$ (Additional file 3: Table S3) were found also validated in the individual lines (Figure 5, Additional file 7: Table S6 and [17]). Thus, it appears likely, that the genes identified in the comparison between $\mathrm{Od}, \mathrm{Hz}$ and the pools play a role in the sensitivity/ tolerance of peach fruit to chilling injury.

\section{ROS-related transcriptomic signatures at harvest and during cold storage: ROSMETER analysis}

A bioinformatic tool which was developed recently for Arabidopsis microarray data [18] to provide an organelle/ type-dependent ROS-related transcriptomic signature was used to further characterize the differential peach responses to cold. ROSEMETER signatures were defined on the basis of transcriptome data obtained in experiments involving plant mutants in antioxidant enzymes or subjected to chemical applications that lead to increases in ROS production, thus providing information on the specificity of the transcriptomic response to oxidative stress. Since we had identified antioxidant system genes as differentially expressed at harvest and increasing in the resistant cultivar after one week at cold storage it was of interest to examine the ROS transcriptomic signature at harvest and during CS for the four fruit types (Figure 7). The ROSMETER analysis indicated that some signatures were capable of discriminating fruits according to their sensitivity to CI. The analysis revealed six distinct groups that clearly can be grouped according to the chilling sensitivity.

Group A includes all the knockout of cytoplasmic ascorbate peroxidase (KO-APX1) experiments, which are thought to represent cytoplasmic $\mathrm{H}_{2} \mathrm{O}_{2}$. These $\mathrm{H}_{2} \mathrm{O}_{2}$ indices correlated positively with sensitivity to $\mathrm{CI}$ before and during cold storage. In agreement a gene encoding a cytosolic ascorbate peroxidase (APX1; PPN071A07 Additional file 6: Table S5) was found among genes in cluster kmeans 5 (Figure 6A), which may be related to a preformed mechanism of cold tolerance, since it is highest at harvest and in inverse relation to cold sensitivity.

Cluster $\mathrm{B}$ includes the indices of the conditional fluorescent $(f l u)$ mutant exposed to light $1 \mathrm{~h}$, ozone and $\mathrm{H}_{2} \mathrm{O}_{2}$ treatments. All fruit at harvest showed negative correlations with these indices, but after cold storage, the most sensitive fruit (i.e., Pop-DG pools) showed positive correlations, being, in general, higher in pool S. This suggests that scavenging systems for apoplastic ROS and chloroplastic singlet oxygen could be active at harvest, but decrease during cold storage in parallel with sensitivity to CI.

Cluster C, which showed increase in $\mathrm{Hz}, \mathrm{LS}$ and $\mathrm{S}$ fruit during storage, corresponds to rotenone treatments (3 and $12 \mathrm{~h}$ ), an inhibitor of mitochondrial complex I, (i.e., NADH: ubiquinone oxidoreductase). Rotenone is associated with a mitochondrial stress but has not been shown 


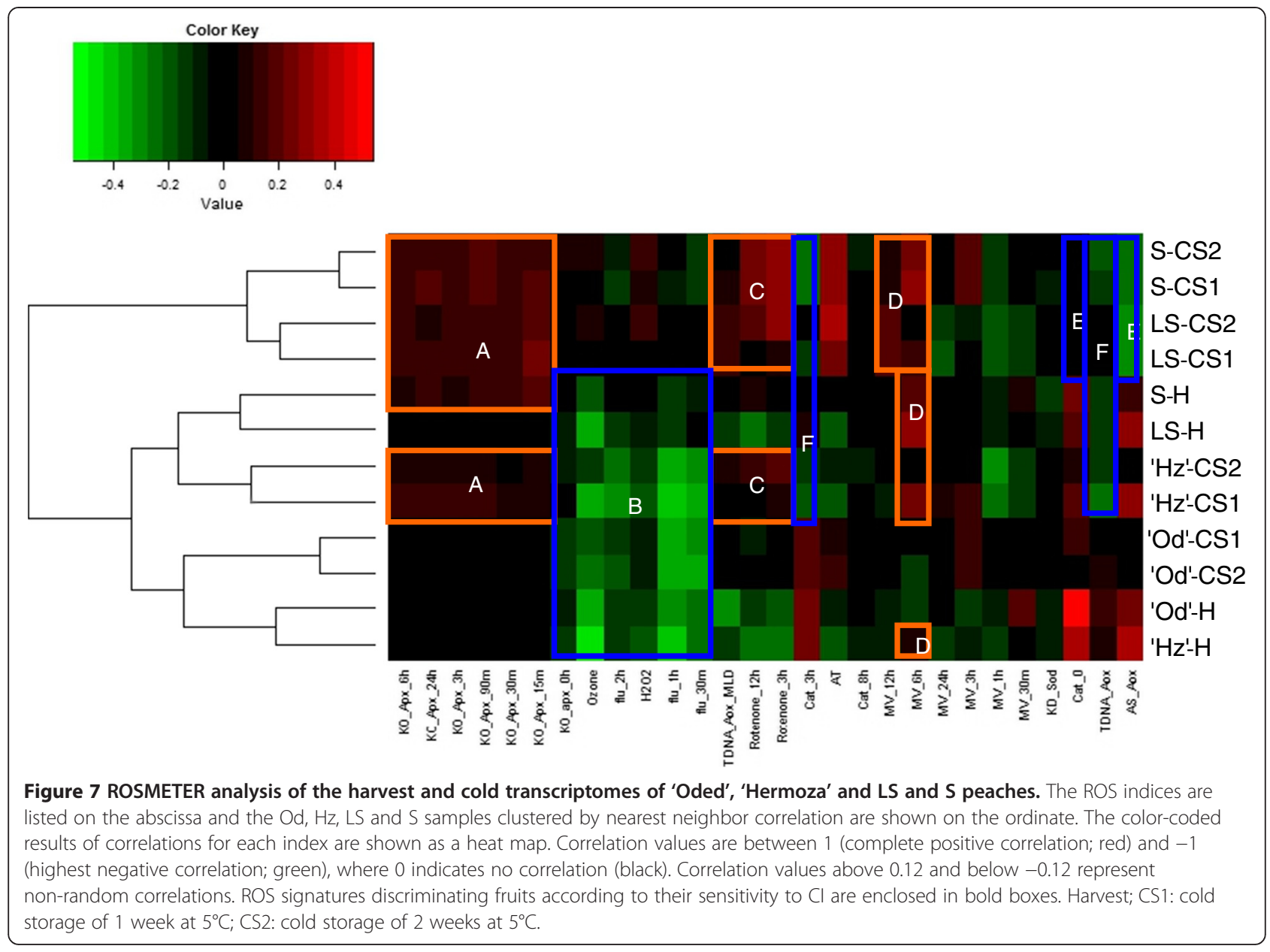

to directly generate ROS [18]. In agreement, four of the 15 genes involved in energy production and enriching in k-means 5 (Figure 6) encode for NADH: ubiquinone oxidoreductase (Additional file 6: Table S5). Therefore low levels of mitochondrial complex I during cold storage could contribute to the sensitivity to cold.

Cluster D corresponds to 6 and $12 \mathrm{~h}$ methylviologen (MV) signatures, indicative of superoxide formation in the chloroplast and mitochondria [29]. 6hMV signature correlated positively with all fruits at harvest and cold stored, sensitive fruits $(\mathrm{Hz}, \mathrm{LS}$ and $\mathrm{S})$, while the most sensitive $\mathrm{S}$ and LS fruits also correlated positively with $12 \mathrm{hMV}$ signature, which may indicate secondary $\mathrm{H}_{2} \mathrm{O}_{2}$ stress effects [18].

Clusters $\mathrm{E}$ and $\mathrm{F}$ basically correlated negatively with sensitivity, included the indices of CAT2 ( 0 and $3 \mathrm{~h}$ ), alternative oxidase mutation (TDNA-AOX1), and alternative oxidase antisense (AS-AOX). The indices CAT2-0 and AS- $A O X$ (cluster $\mathrm{E}$ ) had a negative correlation with $\mathrm{S}$ and LS fruits during cold storage and a positive correlation with the degree of tolerance to $\mathrm{CI}$, especially at harvest. The indices CAT2-3 $\mathrm{h}$ and TDNA-AOX1 (cluster F) correlated negatively with LS and $S$, both at harvest and during cold storage, and with $\mathrm{Hz}$ fruit during cold storage, which agree with data obtained from the direct comparison between $\mathrm{Hz}$ and Od (Figure 3; Additional file 3: Table S3). The fact that fruit tolerance is correlated positively with indices in cluster $\mathrm{E}$ and $\mathrm{F}$, comprising mainly transcriptome data from mutants not exposed to any stress conditions, suggest tolerant fruit might have activated a compensatory scavenging mechanism.

These results indicate that although cultivars presented oxidative stress under cold storage, high levels of antioxidant activities in cytoplasm, mitochondria and chloroplast (chromoplast) are likely contribute to protection in the tolerant fruit.

\section{Discussion}

Integration of data from different peach genotypes and validation of the results

In this study an analysis of fruit transcript levels in response to CS in different peach genotypes is presented. In the first part of the of the study, the transcriptomes of $\mathrm{Od}$ and $\mathrm{Hz}$ at harvest and subjected to CS were analyzed using the Chillpeach microarray (Figures 2, 3 and 4). We validated the microarray data by qRT-PCR of ten 
genes (Additional file 5: Table S4), some of them reported previously to be associated to tolerance to WLT. We observed a high correlation between microarray and qRT-PCR data (Figure 5). The expression patterns of the single genes analyzed were in concordance (Figure 5B and Additional file 5: Table S4), although the level of expression was not confirmed for each gene in each sample. It is known from similar studies that the two technologies of expression analysis deliver qualitatively comparable data, however, the magnitude of such expression changes as reflected by microarray data tends to be generally compressed in comparison with qRT-PCR [16].

In the second part of the experiment, we performed a comparison of transcript levels between $\mathrm{Od}, \mathrm{Hz}$ and two pools from the Pop-DG population (Figure 6 and Additional file 6: Table S5), recently analyzed at transcriptomic level [17]. A number of studies have reported changes in gene expression and protein activity in peach fruit in response to low temperature leading to $\mathrm{CI}$ (reviewed in [2]). However, differences in experimental approaches, genotypes, storage and shelf conditions (time and temperature) and also in the symptom assessment often result in lack of consistency of results [30-32]. In the case of microarray studies, the differences in technologies and cutoffs used for the identification of differentially expressed genes, the different genes represented on each array and technical differences in RNA and hybridization, analysis protocols and references used often hinder the identification of common regulated genes [33]. The expression changes identified in the two large experiments compared here, Od-Hz and S-LS pools, used the same sampling time, technical platform, RNA reference, analysis, protocols and p-values to identify differentially expressed genes, therefore overcoming this issue.

The peach lines in the Pop-DG populations used to produce LS and S pools were less tolerant to cold storage than Od and Hz. However, if the mechanism/program for tolerance was similar, our hypothesis was that genes highly expressed in the LS pool would show high expression levels in the tolerant Od compared to the sensitive counterpart, but the magnitude of the changes could be different. For the comparison we selected differentially expressed genes at one week of storage, the time where greatest differences in CI are observed. This removed considerable biological variation and added to the strength of the comparison. A criticism to our approach could be that we are setting a bias for the common cold regulated genes towards one of the CI symptoms, i.e., WLT.

We found close agreement between the significant changes detected by the two experiments (see Additional file 6: Table S5) and also with the sensitivity degree of individual lines of the Pop-DG population (see Additional file 7: Table S6). The low proportion of genes with opposite changes also supports this contention, and we feel that data from both experiments can be interpreted with confidence. Further, since the fruits of Od, $\mathrm{Hz}, \mathrm{LS}$ and $\mathrm{S}$ pools cover a wide range in $\mathrm{CI}$ sensitivity, this comparison has allowed the identification of a set of genes with shared expression patterns (core cold response) that are candidates to be related to $\mathrm{CI}$ tolerance/sensitivity (Figure 6A, clusters k-means 2, 5 and 9) but also genotype specific responses (Figure 6A, clusters k-means 1, 8 and 11). Genes differentially expressed in one experiment but changing in opposite direction or not changing in the other could indicate a difference in the response due to the genotype or for other reasons [33].

However, although RNA expression data alone is insufficient for establishing a clear link between a gene/protein and the trait of interest, transcriptomics is an important first step to explore potential novel candidate genes for a particular process, which is the goal of this work. The data presented here, reinforce and extend previous reports, and provide insights into processes that are related to CI tolerance/sensitivity rather than simply being responses to cold.

\section{Quantitative differences in the subset of core cold responsive genes correlated with sensitivity to $\mathrm{Cl}$}

Transcripts in the common cold regulated group showed expression values that correlated with sensitivity (Figure 6A). Furthermore, our results indicated that although reprogramming of the transcriptome underlies the core cold responses and the chilling sensitivity in peach fruit, many of these changes depend on the expression levels at harvest (Figure 6A). For the set of core cold responsive up-regulated genes, tolerant cultivars showed low expression levels both at harvest and during cold storage conditions, whereas sensitive cultivars showed increased expression in the cold (Figure 6A, cluster k-means 2 and 9). Interestingly, we could not identify a common core of cold response genes up-regulated in parallel with increased tolerance. This could be due to limitations of the Chillpeach microarray that was constructed with fruit from the PopDG mapping population [16], and which is less tolerant than Od. Alternatively, this may indicate that tolerant fruit were relatively less stressed at the cellular level compared to sensitive fruit and thus have a more limited response of the transcriptome, as has been described for salt and drought stressed rice [34].

\section{Expression of cell wall genes related to WLT at a pre-symptomatic stage}

Alterations in cell wall related transcriptome, cell wall remodeling enzyme activities and in cell wall polymers metabolism in relation to WLT are normally detected during shelf life in cold sensitive cultivars but some have been reported to occur during extended cold storage 
[8,32]. Using Pop-DG siblings, a set of genes related to cell wall remodeling were found differentially expressed between S and LS pools, but no enrichment was found for this functional category [17]. In the current paper, we observed gene expression differences in cell wall genes during cold that could be associated to the eventual WLT phenotype that would develop in shelf life. It has been found that low levels of endo-PG activity combined with continuous activity of pectin methylesterase may lead to altered pectins during CS in fruit and this contributes to WLT when fruit are removed to SL $[8,35]$. Furthermore, endopolygalacturonase (endo-PG) was found in a quantitative trait loci (QTL) on linkage group LG4 for both FBL and WLT [36]. In agreement with this, we found a polygalacturonase inhibiting protein (PGIP), a pectin methyl esterase and pectin acetyl esterase among genes with low expression levels across all cultivars at harvest but which were up-regulated in parallel with increasing fruit sensitivity (k-means 2, Figure 6A; Table 2; Additional file 3: Table S3).

During WLT development in shelf life pectin accumulation was observed in the intercellular spaces and inside parenchyma cells near to vascular bundles [37] and these modifications may begin during CS [8]. Moreover early histological studies indicate that during the last stages of peach fruit ripening a secretory system producing mucilage occurs within the mesocarp vascular bundles [38]. Our previous results have correlated BXL1 ( $\beta$-xylosidase) and SBT1.7/ARA12 (serine protease) with WLT sensitivity in the Pop-DG population (Additional file 7: Table S6 and [17]). Current evidence suggests that these genes are required for the proper configuration of pectins in mucilage in seed and roots (see Table 2 and Additional file 8: Table S7 for references), and that there are analogies between fruit ripening and seed mucilage modification [39]. Here, we found these two genes also among the genes up-regulated by cold in a manner similar to fruit propensity to develop WLT (k-means 2; Figure 6A). Furthermore, among genes in cluster k-means 2 were also orthologs of other genes related to pectin configuration such as MUR4 (UDP-arabinose 4-epimerase) but also orthologs of genes required to control mucilage production and extrusion such as LEUNING (LUG), LUH/MUM1 (Leuning homo$\log$ ), TTG2 (transparent testa glabra 2) and LOS6/ABA1, encoding a zeaxanthin epoxidase (Table 2). TTG2 and $L O S 6 / A B A 1$ regulate mucilage production $[40,41]$ while, LUH/MUM1and LUG, function redundantly in promoting mucilage extrusion [42]. Thus it is likely that the changes in the expression of these genes are setting the stage for the WLT disorder in these pre-symptomatic fruit.

Cluster k-means 2 also includes genes related to noncellulosic cell wall polysaccharide biosynthesis and lignification (Table 2) such as CSLE1 (cellulose synthase like 1), which was previously confirmed to be related to the sensitivity to WLT in individual lines of the Pop-DG population (Additional file 7: Table S6 and [17]) as well IRX14 (irregular xylem 14) CSLE1 (cellulose synthase like 1), IRX4/CCR4 (cinnamoyl Co-A reductase 4), UGT72E1 (UDP-glucosyltransferase 72E1), CAD7/ELI3-1 (cinnamyl alcohol dehydrogenase 7), XCP1 (XYLEM CYSTEINE PEPTIDASE 1) and SND2, a NAC domain protein that regulates the expression of lignin, cellulose and hemicellulose biosynthetic genes involved in secondary cell wall development in Arabidopsis fibers [43]. Thus, in addition to changes in pectin composition and biosynthesis, cold storage activates a secondary cell wall gene expression program in a WLT sensitivity dependence manner. In support of that, genes of cluster k-means 8 and cluster k-means 5 (increasing during CS in Od or associated to tolerance; Figure 6A and Table 3) include orthologs of negative regulators of lignin biosynthesis such as the mybtranscription factor MYB4 [44], WUSCHEL-related homeobox 13 (WOX13) [45], and two the MADS box genes, FRUTIFULL (FUL) and tomato AGAMOUS like TAGL1 (Table 3).

\section{The maintenance of antioxidant systems and metabolites with antioxidant activity correlate with tolerance}

Differences in expression of genes in the group of 'downregulated by cold' could drive many of the responses to cold observed in peaches. These genes were constitutively expressed at high levels in the tolerant group of fruit and down regulated during cold storage in sensitive fruit, while in tolerant fruit they were less affected or even not changed (k-means 5 and 10; Figure 6). Previous studies have suggested that high constitutive gene expression prior to cold stress treatment might be part of a preformed tolerance mechanism in peach fruit $[17,24]$, which may contribute to inhibition of some aspects of ripening and protect fruit during cold storage [17]. In particular, our results indicate that fruit with elevated levels at harvest and during cold storage of genes related to protein biosynthesis, especially ribosomal proteins, energy production, antioxidant systems and genes encoding for activities involved in the biosynthesis of secondary metabolites with antioxidant capacity such as carotenoids, flavonoids and proanthocyanins (k-means 5; Table 3; Additional file 3: Table S3 and Additional file 6: Table S5) were significantly less likely to develop CI. In agreement with these results, among genes correlated to WLT tolerance (cluster k-means 5 in Figure 6A; Table 3) there were the MADS box transcription factors AGAMOUS and FUL1, which have been described in other plants as positive regulators of carotenoid biosynthesis [46,47], flavonoids [46] and anthocyanins [48].

We previously reported that genes of the flavonoid and early proanthocyanin biosynthetic pathways such as chalcone synthase (CHS/TT4), leucoanthocyanidin dioxygenase 
Table 2 Genes discussed in the text correlated with sensitivity degree during cold storage (cluster k-means 2)

\begin{tabular}{|c|c|c|c|c|c|c|c|c|c|}
\hline $\begin{array}{l}\text { Function specific } \\
\text { process }\end{array}$ & $\begin{array}{l}\text { Chillpeach } \\
\text { ID }\end{array}$ & Unigene annotation & Arab AGI & $\begin{array}{l}\text { Arab gene } \\
\text { symbol }\end{array}$ & Hormone signaling & $\begin{array}{l}\text { Sugar signaling/ } \\
\text { partioning }\end{array}$ & $\begin{array}{l}\text { Hormone and } \\
\text { secondary } \\
\text { metabolite } \\
\text { biosynthesis } \\
\text { regulation }\end{array}$ & $\begin{array}{l}\text { Cell wall and } \\
\text { cytoesqueleton } \\
\text { related }\end{array}$ & Cell polarity \\
\hline
\end{tabular}

regulation

Aminoacid metabolism

\begin{tabular}{|c|c|c|c|}
\hline \multirow[t]{2}{*}{$\begin{array}{l}\text { Alanine and } \\
\text { Aspartate } \\
\text { metabolism }\end{array}$} & PPN065C10 & $\begin{array}{l}\text { Putative aspartate } \\
\text { aminotransferase }\end{array}$ & AT1G80360 \\
\hline & PPN080E12 & $\begin{array}{l}\text { Putative aspartate } \\
\text { aminotransferase }\end{array}$ & AT1G80360 \\
\hline
\end{tabular}

\section{Cell wall related}

Cellulose

biosynthesis

PPN046D09 Cellulose synthase-like AT1G55850 CSLE1 protein CsIG

Hemicellulose

biosynthesis

PPN036E12 Glycosyltransferase

AT4G36890 IRX14

Hemicellulose

degradation

$$
\begin{aligned}
\text { PP1002E04 } & \begin{array}{l}
\text { Alpha-L- } \\
\text { arabinofuranosidase/ } \\
\text { beta-D-xylosidase }
\end{array}
\end{aligned}
$$

AT5G49360 BXL1

Pectin degradation

PPN041B11 Polygalacturonaseinhibiting protein

AT5G06860 PGIP1

PPN047G10 Polygalacturonase-like AT4G23500 protein

Pectin methylesterification
PP1004E01 Putative
pectinesterase
PPN001F02 Pectinacetylesterase
family protein
PPN066B05 Ripening-related protein-like
PPN062D06 UDP-arabinose
AT2G26440
AT5G23870
AT5G51520

UDP-L-arabinose,

UDP-galacturonate 4-epimerase 1

and UDP-xylose

Protein degradation

Negative

regulation of Trp-

IAA and ET

biosynthesis

Negative

regulation of Trp-

IAA and ET

biosynthesis
SCW biosynthesis;

hemicellulose

biosynthesis

SCW biosynthesis;

hemicellulose

glucuronoxylan

biosyntheis

Pectin metabolism;

trim b-xylan and a-

arabinan side groups

from the RG I.

Inhibition of

degradation of the

polygalacturonan

Sugar signaling

biosynthesis 
Table 2 Genes discussed in the text correlated with sensitivity degree during cold storage (cluster k-means 2) (Continued)

\section{Protease \\ AT5G67360 SBT1.7/}

$$
\text { ARA12 }
$$

PPN009E02 Cysteine protease $14 \quad$ AT4G35350 XCP1

\section{RNA transcription regulation}

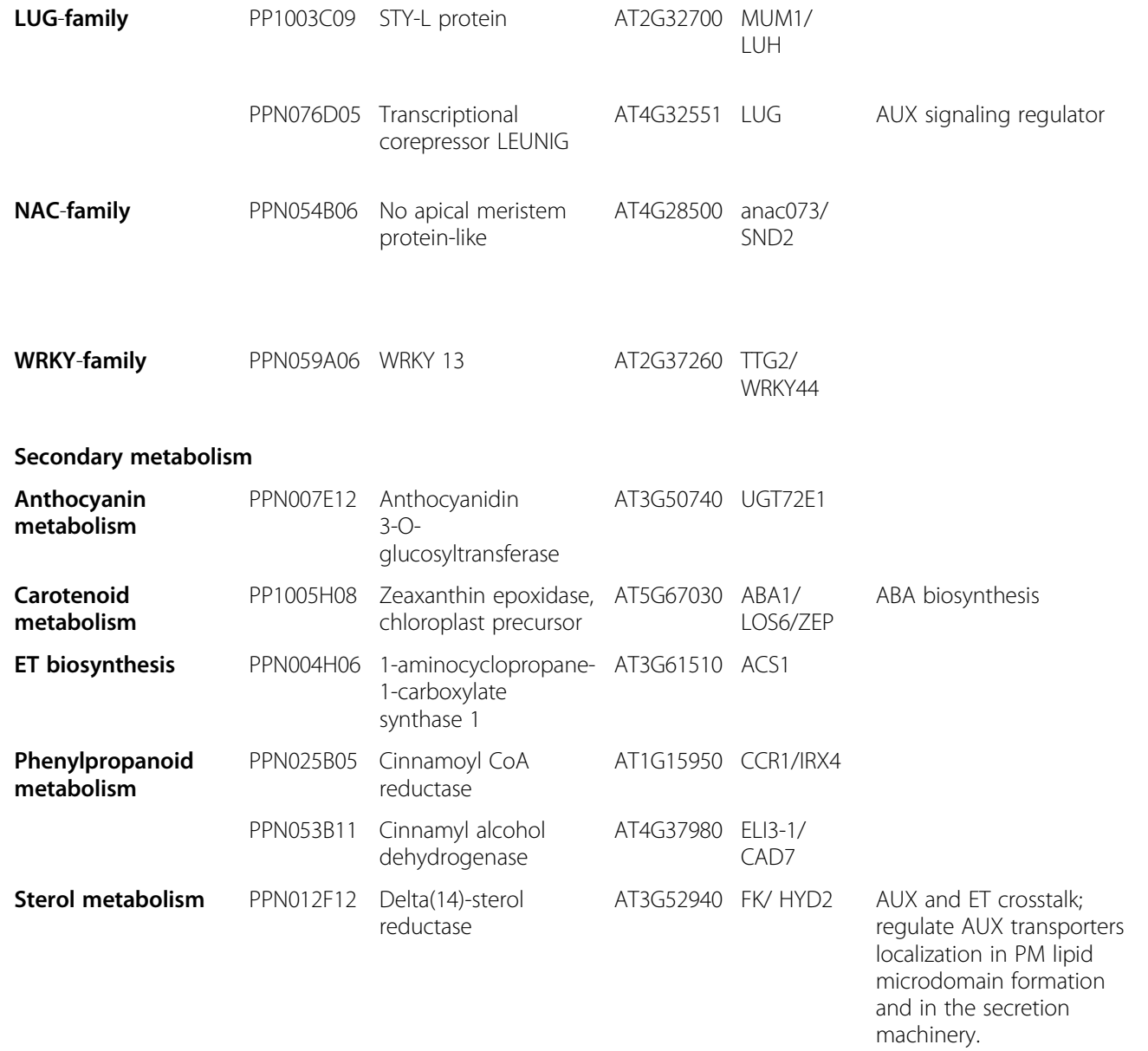

Indirectly affects the pectin methylation status of mucilage and/or the primary CW

SCW biosynthesis; postive regulation of thacheray element differentialion

Control mucilage production and extrusion

Control mucilage production and extrusion

SCW biosynthesis; postive regulator of lignin, cellulose and hemicellulose biosyntehsis

Anthocyanin/PA mucilage production polimerization regulation regulation

SCW biosynthesis; lignin biosynthesis

Mucilage production regulation

ET biosynthesis

SCW biosynthesis, lignin biosythesis SCW biosynthesis; lignin biosythesis

Cellulose, callose and Polar targeting of lignin, VN proteins to the development PM;Lipid microdomains 
Table 2 Genes discussed in the text correlated with sensitivity degree during cold storage (cluster k-means 2) (Continued)

\section{PPN063B12 Helix-turn-helix AT4G37760 SQE3}

Terpene metabolism PPN068G10 Beta-amyrin synthase AT1G78950 BAS

Signal transduction pathway

\begin{tabular}{|c|c|c|c|c|c|c|}
\hline $\begin{array}{l}\text { ABA signaling } / \mathrm{Ca} \\
\text { signal transducer }\end{array}$ & PPN069F09 & $\begin{array}{l}\text { Putative serine/ } \\
\text { threonine protein } \\
\text { kinase PK11-C1 }\end{array}$ & AT4G33950 & $\begin{array}{l}\text { OST1/ / } \\
\text { SRK2E/ } \\
\text { SNRK2-6 }\end{array}$ & ABA & $\begin{array}{l}\text { Sucrose } \\
\text { metabolism } \\
\text { regulation }\end{array}$ \\
\hline $\begin{array}{l}\text { ABA signaling/ABF } \\
\text { phosphorylation }\end{array}$ & PPN010B11 & $\begin{array}{l}\text { Serine-threonine } \\
\text { protein kinase }\end{array}$ & AT1G78290 & $\begin{array}{l}\text { SNRK2.8/ } \\
\text { SRK2C }\end{array}$ & ABA & sucrose signaling \\
\hline $\begin{array}{l}\text { Phosphorylation } \\
\text { cascades/metabolic }\end{array}$ & PPN054E02 & AKIN beta3 & AT2G28060 & KINß3 & ABA & sucrose signaling \\
\hline
\end{tabular}

switch

Trafficking machinery and membrane dynamics

ER to Golgi

PP1003D05 Root hair defective 3

GOM8

AUX, ET

Sphingolipid

metabolism

PPN021D05 Similar to alkaline
ceramidase

AT1G07380

PPN031D01 similar to alkaline

ceramidase

AT1G07380

Transport

apoplast

PPN070B12 Multidrug resistance protein 11

AT3G28860 PGP19/ MDR11/ ABCB19

AUX transport into ER

PP1004E09 Auxin Efflux Carrier family protein.

PPN075H08 Auxin Efflux Carrier family protein

Carbohydrate PPN046B03 Sorbitol transporter

transport

Cooper transport

PPN040A04 Copper transport protein-like

Ion transporter

activity
PPN016B02 Senescenceassociated
AUX transport

AUX transport

AUX transport sugar partioning and homeostasis

AT2G17500 PILS5

AT3G18830 PMT5/ PLT5
AT3G13870 RHD3/

$\begin{array}{ll}\text { Required for } \mathrm{CW} & \text { Cell polarity } \\ \text { biosynthesis and actin } & \text { regulation }\end{array}$

organization
Ceramide

biosynthesis/ degradation

Ceramide

biosynthesis/ degradation
Polar targeting of proteins to the

PM;Lipid

microdomains

Polar targeting of

proteins to the

PM;Lipid

microdomains 
Table 2 Genes discussed in the text correlated with sensitivity degree during cold storage (cluster k-means 2) (Continued)

\begin{tabular}{|c|c|c|c|c|}
\hline \multirow[t]{2}{*}{ Metal-ion transport } & PP1005G08 & $\begin{array}{l}\text { Metal tolerance } \\
\text { protein C2 }\end{array}$ & AT3G12100 & MTP5 \\
\hline & PPN007G12 & $\begin{array}{l}\text { Metal transporter } \\
\text { Nramp3 }\end{array}$ & AT2G23150 & ATNRAMP3 \\
\hline Oligopepetide & PPN029A02 & Putative peptide & AT3G01350 & \\
\hline
\end{tabular}

Abbreviations: AUX: auxin; ET; ethylene; ABA: Abcisic acid; PM: plasma membrane; CW: cell wall; SCW: secondary cell wall; ER: endoplasmic reticulum; MVB/LE: microvesicular body/late endosome; TGN/EE: trans-golgy network/early endosome; VSR: vacuolar sorting receptors VN: vascular networks; PA: proanthocyanines; PIN; PIN formed auxin efflux carrier; RG:rhamnogalacturonan; XyG: xyloglucan.

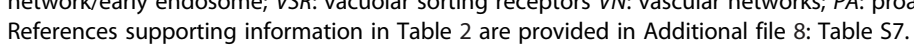


Table 3 Genes discussed in the text correlated with tolerance

\begin{tabular}{|c|c|c|c|c|c|c|c|c|c|}
\hline Function Specific process & $\begin{array}{l}\text { Chillpeach } \\
\text { ID }\end{array}$ & Unigene annotation & Arab AGI & $\begin{array}{l}\text { Arab } \\
\text { gene } \\
\text { symbol }\end{array}$ & Hormone signaling & $\begin{array}{l}\text { Sugar } \\
\text { signaling/ } \\
\text { partioning }\end{array}$ & $\begin{array}{l}\text { Hormone and } \\
\text { secondary } \\
\text { metabolite } \\
\text { biosynthesis } \\
\text { regulation }\end{array}$ & $\begin{array}{l}\text { Cell wall and } \\
\text { cytoesqueleton } \\
\text { related }\end{array}$ & $\begin{array}{l}\text { Cell } \\
\text { polarity }\end{array}$ \\
\hline
\end{tabular}

k-means 5. Correlated with tolerance at harvest and during cold storage

Aminoacid metabolism

Cyanide detoxification

PPN075E10 Beta-cyanoalanine AT3G61440 CYSC1 synthase 1

Methionine metabolism

PPN034A06 1,2-dihydroxy-3-keto-

5-methylthiopentene

AT5G43850 ARD4 dioxygenase 4

PPN034C12 1,2-dihydroxy-3-keto- AT4G14710 ARD2 5-methylthiopentene dioxygenase 3

PPN072E05 Cystathionine gamma AT3G01120 MTO1/

$$
\text { synthase }
$$

\section{Antioxidant system}

GLUTHATHIONE-

GLUTAREDOXIN AND

THIOREDOXIN REDOX

PPN039H11 Glutathione Stransferase

$$
\begin{aligned}
\text { AT5G17220 TT19/ } \\
\text { GSTF12 }
\end{aligned}
$$

regulation

HOMEOSTASIS

\section{Cytoskeleton organization and biogenesis}

Actin microfilament-actin depolimerization

PPN047E05 Actin depolymerizing AT5G59880 ADF3 factor 2

Microtubule-Microtubule

binding and stabilization

PPN073D05 Microtubule-

associated proteins

Microtubule-microtubule

organization and formation

PPN075E12 Tubulin folding

cofactor B

AT3G10220 EMB2804/

RNA transcription regulation

AP2/EREBP family

PPN054F05 AP2-related

$$
\text { transcription factor }
$$

AT5G47220 ERF2 ET signaling

Yang Cycle

Yang Cycle

Yang Cycle

PA monomer

transporter
AUX/IAA family

LIM-family
PPN014H03 Auxin-induced protein AT1G04250 AXR3/ AUX28 IAA17

AUX and ABA nuclear signaling; negative regulator

PPN057F01 AUX/IAA protein

AT4G29080 PAP2/

IAA27

AUX nuclear signaling

negative regulator

PPN009B01 Pollen-specific protein AT1G10200 WLIM1 SF3, putative

$\begin{array}{ll}\text { PPN069C01 AT1G10200 WLIM } & \text { W }\end{array}$ 
Table 3 Genes discussed in the text correlated with tolerance (Continued)

\begin{tabular}{|c|c|c|c|c|c|c|c|c|}
\hline & & $\begin{array}{l}\text { Transcription factor } \\
\lim 1\end{array}$ & & & & & & $\begin{array}{l}\text { Actin stabilizing } \\
\text { protein }\end{array}$ \\
\hline \multirow[t]{2}{*}{ MADS-box family } & PP1006G03 & $\begin{array}{l}\text { MADS-box } \\
\text { transcription factor }\end{array}$ & AT5G60910 & $\begin{array}{l}\text { FUL/ } \\
\text { AGL8 }\end{array}$ & & & $\begin{array}{l}\text { Positive regulatior of } \\
\text { caroterne and } \\
\text { anthocyanin } \\
\text { biosynthesis, }\end{array}$ & $\begin{array}{l}\text { Negative regulation of } \\
\text { lignin }\end{array}$ \\
\hline & PPN042H02 & MADS4 & AT4G18960 & AG & ET up-regulation & & $\begin{array}{l}\text { Postisitive carotene } \\
\text { biosynthesis } \\
\text { regulation; }\end{array}$ & $\begin{array}{l}\text { Negative regulation of } \\
\text { lignin biosynthesis }\end{array}$ \\
\hline \multicolumn{9}{|c|}{ RNA translation and protein assembly } \\
\hline $\begin{array}{l}\text { Regulation of protein } \\
\text { biosynthesis }\end{array}$ & PPN006H04 & $\begin{array}{l}\text { Translationally- } \\
\text { controlled tumor } \\
\text { protein homolog }\end{array}$ & AT3G16640 & TCTP & $\begin{array}{l}\text { AUX cytoplasmic } \\
\text { signaling }\end{array}$ & $\begin{array}{l}\text { Sugar } \\
\text { signaling }\end{array}$ & & $\begin{array}{l}\text { CW biosynthesis } \\
\text { regulation }\end{array}$ \\
\hline \multicolumn{9}{|l|}{ Secondary metabolism } \\
\hline \multirow[t]{2}{*}{ Anthocyanin metabolism } & $\begin{array}{l}\text { PpLDOX } \\
\text { (PpLDOX) }\end{array}$ & $\begin{array}{l}\text { Leucoanthocyanidin } \\
\text { dioxygenase }\end{array}$ & & PpLDOX & & & $\begin{array}{l}\text { Flavonoid/PA } \\
\text { biosynthesis }\end{array}$ & \\
\hline & PPN055C03 & $\begin{array}{l}\text { Anthocyanidin } \\
\text { reductase }\end{array}$ & AT1G61720 & BAN & & & PA biosynthess & \\
\hline Aspartate biosyntheis & PPN046D06 & $\begin{array}{l}\text { 1-aminocyclopropane- } \\
\text { 1-carboxylate } \\
\text { synthase }\end{array}$ & AT1G62960 & ACS10 & & & & \\
\hline \multirow[t]{2}{*}{ Carotenoid metabolism } & PPN006A10 & Phytoene synthase & AT5G17230 & PSY & & & & \\
\hline & PPN067A01 & $\begin{array}{l}\text { Capsanthin/ } \\
\text { capsorubin synthase }\end{array}$ & AT3G10230 & LYC & & & & \\
\hline \multirow[t]{2}{*}{ Cyanide detoxification } & PP1000E01 & Cyanate hydratase & AT3G23490 & CYN & & & & \\
\hline & PPN066B01 & $\begin{array}{l}\text { Nitrilase/cyanide } \\
\text { hydratase and } \\
\text { apolipoprotein } \mathrm{N} \text { - } \\
\text { acyltransferase family } \\
\text { protein }\end{array}$ & AT5G12040 & & & & & \\
\hline \multirow[t]{2}{*}{ Flavonoid metabolism } & PPN050G05 & $\begin{array}{l}\text { Dihydroflavonol 4- } \\
\text { reductase-like }\end{array}$ & AT5G58490 & & & & $\begin{array}{l}\text { Flavonoid/PA } \\
\text { biosynthesis }\end{array}$ & \\
\hline & PPN052H09 & Chalcone synthase 2 & AT5G13930 & $\mathrm{CHS} / \mathrm{TT} 4$ & $\begin{array}{l}\text { Negative regulation of } \\
\text { AUX transport }\end{array}$ & & & \\
\hline \multicolumn{9}{|l|}{ Signal transduction pathway } \\
\hline Cytoplasmic TOR signaling & PPN076G10 & $\begin{array}{l}\text { Protein lethal with sec } \\
\text { thirteen } 8-2\end{array}$ & AT3G18140 & LST8-1 & $\begin{array}{l}\text { AUX cytoplasmic } \\
\text { signaling }\end{array}$ & $\begin{array}{l}\text { Sugar } \\
\text { signaling }\end{array}$ & & $\begin{array}{l}\text { CW biosynthesis } \\
\text { regulation }\end{array}$ \\
\hline $\begin{array}{l}\text { ET signaling/ET signal } \\
\text { transduction }\end{array}$ & PPN011G11 & GTP-binding protein & AT3G46060 & $\begin{array}{l}\text { ARA3/ } \\
\text { RAB8A }\end{array}$ & ET signaling & & & \\
\hline
\end{tabular}


Table 3 Genes discussed in the text correlated with tolerance (Continued)

\begin{tabular}{|c|c|c|c|c|c|c|c|}
\hline $\begin{array}{l}\text { CME;EE;internalization and } \\
\text { intracellular trafficking of PM } \\
\text { proteins }\end{array}$ & PPN011F03 & Clathrin_L-chain & AT2G40060 & CLC2 & $\begin{array}{l}\text { Regulates cellular AUX } \\
\text { levels by controlling the } \\
\text { abundance and } \\
\text { distribution of PIN } \\
\text { proteins at the PM }\end{array}$ & & $\begin{array}{l}\text { Cell } \\
\text { polarity } \\
\text { regulation }\end{array}$ \\
\hline $\begin{array}{l}\text { CME;internalization and } \\
\text { intracellular trafficking of PM } \\
\text { proteins }\end{array}$ & PPN017G03 & $\begin{array}{l}\text { Calcium-binding } \\
\text { EF-hand }\end{array}$ & AT3G01780 & TPLATE & $\begin{array}{l}\text { Regulates cellular AUX } \\
\text { levels by controlling the } \\
\text { abundance and } \\
\text { distribution of PIN } \\
\text { proteins at the PM }\end{array}$ & $\begin{array}{l}\text { Regulation of } \\
\text { cellulose synthesis by } \\
\text { controlling the } \\
\text { abundance of active } \\
\text { CESA complexes at } \\
\text { the PM }\end{array}$ & $\begin{array}{l}\text { Cell } \\
\text { polarity } \\
\text { regulation }\end{array}$ \\
\hline Endosomal sorting complex & PPN060A04 & $\begin{array}{l}\text { Putative endosomal } \\
\text { Vps protein complex } \\
\text { subunit }\end{array}$ & AT5G22950 & VPS24.1 & $\begin{array}{l}\text { Required for internalize } \\
\text { PIN1, PIN2, and AUX1 to } \\
\text { the MVB/ LE for vacuolar } \\
\text { degradation }\end{array}$ & & \\
\hline Golgy to ER/COPI vesicles & PPN044E10 & $\begin{array}{l}\text { ARF-like small GTPase } \\
1\end{array}$ & AT2G47170 & $\begin{array}{l}\text { ARF1A1C/ } \\
\text { BEX1 }\end{array}$ & $\begin{array}{l}\text { Essential for recycling of } \\
\text { PIN transporters to the } \\
\text { PM and for vacuolar } \\
\text { targeting }\end{array}$ & & $\begin{array}{l}\text { Cell } \\
\text { polarity }\end{array}$ \\
\hline \multirow[t]{2}{*}{$\begin{array}{l}\text { Retromer complex;LE to } \\
\text { vacuole }\end{array}$} & PPN007G03 & $\begin{array}{l}\text { Sorting nexin-like } \\
\text { protein }\end{array}$ & AT5G06140 & SNX1 & $\begin{array}{l}\text { Regulates both the } \\
\text { recycling VSR from the } \\
\text { TGN/ EE to the ER and } \\
\text { the balance between } \\
\text { vacuolar degradation and } \\
\text { recycling of PIN proteins }\end{array}$ & & \\
\hline & PPN023B01 & $\begin{array}{l}\text { Ras-related protein } \\
\text { Rab7 }\end{array}$ & AT3G18820 & $\begin{array}{l}\text { RABG3F/ } \\
\text { RAB7B }\end{array}$ & & & \\
\hline \multicolumn{8}{|c|}{ k-means 8. Associated with high tolerance to chilling injury } \\
\hline \multicolumn{8}{|l|}{ Aminoacid metabolism } \\
\hline AUX biosynthesis & PPN058D11 & $\begin{array}{l}\text { Anthranilate synthase } \\
\text { beta subunit }\end{array}$ & AT1G25220 & ASB1 & AUX biosynthesis & & \\
\hline \multicolumn{8}{|l|}{ RNA transcription regulation } \\
\hline \multirow[t]{2}{*}{ AUX/IAA family } & PP1009D02 & IAA16 protein & AT1G04250 & $\begin{array}{l}\text { AXR3/ } \\
\text { IAA17 }\end{array}$ & $\begin{array}{l}\text { AUX and ABA nuclear } \\
\text { signaling; negative } \\
\text { regulator }\end{array}$ & & \\
\hline & PPN060G07 & AUX/IAA protein & AT1G04240 & $\begin{array}{l}\text { IAA3/ } \\
\text { SHY2 }\end{array}$ & $\begin{array}{l}\text { AUX nuclear signaling; } \\
\text { negative regulator }\end{array}$ & & \\
\hline HD-ZIP family & PPN074H05 & $\begin{array}{l}\text { HB2 homeodomain } \\
\text { protein }\end{array}$ & AT4G35550 & $\begin{array}{l}\text { HB-4/ } \\
\text { WOX13 }\end{array}$ & AUX regulated & $\begin{array}{l}\text { SCW biosynthesis; } \\
\text { negative regulator } \\
\text { lignin biosynthesis }\end{array}$ & \\
\hline MYB-family & PPN067A04 & $\begin{array}{l}\text { MYB-like DNA-binding } \\
\text { domain protein }\end{array}$ & AT4G38620 & MYB4 & & $\begin{array}{l}\text { SCW biosynthesis; } \\
\text { negative regulator } \\
\text { lignin biosynthesis }\end{array}$ & \\
\hline
\end{tabular}


Table 3 Genes discussed in the text correlated with tolerance (Continued)

Signal transduction pathway

PPN054G06 Ethylene receptor AT3G04580 EIN4

ET signaling

Transport

Cooper transport

PPN035H02 Copper-transporting AT5G44790 RAN1

ET signaling; delivers

cooper ion into the ET

receptors; is required for

both ET binding and the

receptor functionality

Abbreviations: AUX:auxin; $E T$; ethylene; $A B A$ : Abcisic acid; PM:plasma membrane; $C W$ : cell wall; SCW: secondary cell wall; ER: endoplasmic reticulum; MVB/LE: microvesicular body/late endosome; TGN/EE:trans-golgy network/early endosome; VSR: vacuolar sorting receptors VN:vascular networks; PA: proanthocyanines; PIN; PIN formed auxin efflux carrier; $R G$ : rhamnogalacturonan; XYG: xyloglucan.

References supporting information in Table 3 are provided in Additional file 8: Table S7. 
(PpLDOX) and glutathione $S$-transferase 12 (GST12/TT19) were part of a preformed mechanism associated with cold tolerance $[17,24,49]$. The results here confirm these results (Table 3) and expand the list of genes related to these biosynthetic pathways to dihydroflavonol 4-reductase (DFR) and the ortholog of BANYUS (BAN), an anthocyanidin reductase (cluster k-means 5 in Figure 6A and Table 3). However, among genes in cluster k-means 2 (induced by cold in a sensitivity related manner) and k-means 1 (specific for high sensitivity to WLT) was the WRKY family transcription factor TTG2 (transparent testa glabra 2), which not only modulates mucilage production but also polymerization of proanthocyanidins [40] and AHA10, a putative P-type $\mathrm{H}^{+}$-ATPase involved in proanthocyanidin transport and polymerization (Tables 2 and 4). Interestingly, mutations in both, TTG2 and AHA10, increase the levels of proanthocyanidin monomers (i.e., catechin and epicatechin) [40,50]. Epicatechin showed negative correlation with chilling injury in peach fruit [51]. Taken together with this work, our results indicate that proanthocyanidin monomers may accumulate in tolerant fruit, while polymerized forms could be dominant in sensitive fruit.

In addition, the ROSMETER results (Figure 7) suggest a genetic program for high levels of antioxidant activities in cytoplasm, mitochondria and chloroplast (chromoplast) in CI tolerant peach fruit, which correlated well with the expression of several genes of the antioxidant system or mitochondrial electron chain (particularly the ROS production site in mitochondria). Consistent with this, cold tolerance and cold acclimation have been associated with higher expression levels of antioxidant/scavenging systems, effective mitochondrial transport and protein synthesis in peach $[17,24,52]$ and other plants [53-55]. In addition, ROSMETER results suggest tolerant fruit might have activated a compensatory scavenging mechanism [18]. Both direct comparison between $\mathrm{Od}$ and $\mathrm{Hz}$ and ROSMETER analysis highlight CAT2 as associated to the sensitivity to chilling (Additional file 3: Table S3; Figure 7). The reductive thiol pathways appear to compensate quite rapidly for catalase deficiency, leading to a new, more oxidized cellular redox state, notably reflected in adjustments of thiol-disulphide status [56]. In agreement, Od fruit had higher number and higher expression levels of genes related to gluthathione-glutaredoxin and thioredoxin redox homeostasis than the sensitive fruit (Additional file 3: Table S3) and the expression of these genes is correlated positively with tolerance (cluster k-means 5 and 8; Additional file 6: Table S5).

\section{A link between WLT at a pre-symptomatic stage and auxin responses and distribution}

Our previous study [17] suggested that auxins play a role in the sensitivity/tolerance program induced by cold storage in peach fruit. We found that the expression of the of auxin transporters and positive regulators of nuclear auxin signaling correlated positively with the future WLT, while the expression of negative regulators of auxin signaling was associated with tolerance [17]. In support of this, clusters k-means 1,2 , and 9 (with higher levels in sensitive fruit; Figure 6A) include orthologs of plasma membrane and endoplasmic reticulum auxin efflux carriers (ABCB19/PGP19, PILS5 and PILS6; Table 2) as well nuclear signaling elements such as cullin CUL1/ AXR6 and the auxin receptor TIR1/AXR1 (Tables 4 and Table 5). Also in agreement with our previous work, IAA/ AUX proteins such as AXR3/IAA17 and IAA27 and SHY2/IAA3 (Table 3), encoding a negative regulators of auxin responses [57] were found in clusters k-means 5 and 8 (preformed tolerance and high-tolerance, respectively, Figure 6A). The expression of the ortholog of IAA27 is further supported by the qRT-PCR results (Figure 5B and Additional file 5: Table S4) and by the positive correlation of the ortholog of IAA27 with the degree of tolerance in individual lines from the Pop-DG population (Additional file 7: Table S6 and [17]).

The results here also highlight new auxin related genes as candidates to be involved in the tolerance/sensitivity to CS. The ortholog of anthranilate synthase (ASB1/WEI7), which is required for IAA synthesis (Table 3), was highly expressed in tolerant fruit in CS ( $\mathrm{k}$-means 8; Figure 6). Further, in cluster k-means 5 (high expression at harvest associated to tolerance, decreasing in storage; Table 3) are the translationally controlled tumour protein (TCTP) and LST8 (lethal with SEC13 protein 8), components of the TOR (target of rapamycin) signaling pathway, an integral part of the cytosolic auxin signaling pathway [58] that connects hormonal and nutrient pathways [59].

Taken together, the differential expression of several genes for auxin homeostasis, transport and signaling supports a strong connection between auxin metabolism and the CI tolerant/sensitive character of peach fruit. But how does auxin link with the expression changes observed for genes related to cell wall, antioxidants and other possible molecular signatures associated to WLT development at the pre-symptomatic stage? Evidence suggests that auxin can affect cell wall structure through both transcriptional, and non-transcriptional mechanisms, such the acidification-linked loosening of the wall (reviewed in [60]) and the TOR pathway [61]. We found that low levels of expression of TOR components were associated to sensitivity (cluster k-means 5, Figure 6A). Inhibition of TOR signaling caused specific changes to pectins and arabinogalactan protein components of cell walls [61]. However, via the cytoplasmic TOR pathway [59] auxin increases the overall cytoplasmic protein synthetic capacity of the cell [62]. This agrees with the higher levels of cell wall related genes in sensitive fruit and with the higher levels of genes related to protein biosynthesis in tolerant 
Table 4 Genes discussed in the text associated to high sensitivity to WLT and FB

Function Chillpeach ID Unigene Arab AGI Arab Hormone

specific

annotation

Arab

Hormone

Sugar

Hormone and

Cell wall and
cytoesqueleton related

Cell polarity

process

symbol

partioning

metabolite

biosynthesis

regulation

k-means 1. Associated with high sensitivity to WLT

Energy production

Plasma membrane ATP production

RNA transcription regulation

b-HLH family

PPN080F10 Prf interactor 30137

Plasma membrane

AT1G17260 AHA10

AT)

AT2G35940 BLH

HB-family

$$
\begin{array}{ll}
\text { PPN069A12 } & \text { BEL1-like } \\
& \text { homeodomain } \\
& \text { transcription factor }
\end{array}
$$

\section{Signal transduction pathway}

AUX signaling/AUX

receptor E3 ubiquitin

ligase SFC-TIR

AUX signaling/Nuclear

signaling pathway

Calcium signaling/

Calcium sensor-

transducer

\section{Calcium signaling/}

Calcium signal

transducer

ET signaling

PPN078E01 Transport inhibitor response 1 protein

AT3G62980 TIR

AT1G05180 AXR1

PPN078G01 Putative auxinresistance protein

PPN027B08 Calcium-dependent protein kinase

PPN013H01 Serine/ threonine kinase

PPN020F10 CBL-interacting protein kinase

PPN057C10 Ethylene signaling protein

ET signaling/Culin E3 ubiquitin ligase

Phosphorylation cascades/MAPK

$$
\begin{array}{ll} 
& \begin{array}{l}
\text { overproduction } \\
\text { protein } 1
\end{array} \\
\text { PPN020H02 } & \text { Mitogen-activated }
\end{array}
$$
protein kinase 4
AT1G05180 AXR1

AT3G57530 CPK32

AT5G58380 CIPK10/

$$
\text { SIP1/ }
$$$$
\text { SNRK3.8 }
$$

AT4G30960 SNRK3.14/ CIPK6/ SIP3

AT5G03280 EIN2

ABA

AT3G51770 ETO1

AT4G01370 MPK4

AUX nuclear

signaling

ABA

$A B A$
AUX nuclea

\section{sucrose signaling}

Ethylene biosynthesis;

positive regulator of ACS

type I and negative

regulator of ACS type II

repressor of ET

biosynthesis (inhibits type

II ACS)
VN establishment,

maintenance, cell number and pattern 
Table 4 Genes discussed in the text associated to high sensitivity to WLT and FB (Continued)

Phosphorylation

(ation

switch

Phosphorylation

cascades/

$$
\begin{array}{ll}
\text { PPN037E11 } & \text { Ser/thr protein } \\
& \text { phosphatase } 2 \mathrm{~A} \\
& \text { regulatory subunit } \mathrm{B}^{\prime} \\
& \text { gamma isoform }
\end{array}
$$

Transport

$$
\begin{aligned}
& \text { Carbohydrate transport PPN025D11 SLT1 protein } \\
& \text { AT3G12570 FYD } \\
& \begin{array}{cl}
\text { PPN078G04 } & \text { Putative membrane } \\
\text { transporter }
\end{array} \\
& \text { AT2G43330 INT } \\
& \text { PPN028F10 Oligopeptide } \\
& \text { transporter OPT } \\
& \text { superfamily }
\end{aligned}
$$

k-means 11. Associated with high sensitivity to $F B$

Aminoacid metabolism

$$
\begin{aligned}
\text { GABA biosynthesis } \quad \text { PPN044B12 } & \begin{array}{l}
\text { Glutamate } \\
\text { decarboxylase, } \\
\text { putative }
\end{array}
\end{aligned}
$$

Pyruvate and Reactive carbonyl species
Conversion of
PP1002C02
oxalacetate to PEP
carboxykinase [ATP]
Pyruvate conversion to
acetyl-CoA
PPN054C12 Pyruvate
dehydrogenase

Sucrose signaling

Yang Cycle regulation tioning and

homeostasis

Sugar partioning and

homeostasis 
Table 4 Genes discussed in the text associated to high sensitivity to WLT and FB (Continued)

\begin{tabular}{|c|c|c|c|c|c|}
\hline & PPN059C05 & $\begin{array}{l}\text { Pyruvate } \\
\text { dehydrogenase E1 } \\
\text { beta subunit } \\
\text { isoform } 3\end{array}$ & AT5G50850 & $\begin{array}{l}\text { MAB1/ } \\
\text { PDHE1- }\end{array}$ & \\
\hline \multirow[t]{3}{*}{$\begin{array}{l}\text { Pyruvate-lactate } \\
\text { interconversions }\end{array}$} & PP1006E06 & $\begin{array}{l}\text { Aldehyde } \\
\text { dehydrogenase } \\
\text { putative }\end{array}$ & AT1G44170 & $\begin{array}{l}\text { ALDH4/ } \\
\text { ALDH3H1 }\end{array}$ & $\mathrm{ABA}$ \\
\hline & PPN035E06 & $\begin{array}{l}\text { Aldehyde } \\
\text { dehydrogenase }\end{array}$ & AT1G44170 & $\begin{array}{l}\text { ALDH4/ } \\
\text { ALDH3H1 }\end{array}$ & $\mathrm{ABA}$ \\
\hline & PPN038B05 & $\begin{array}{l}\text { Aldehyde } \\
\text { dehydrogenase, } \\
\text { putative }\end{array}$ & AT1G44170 & $\begin{array}{l}\text { ALDH4/ } \\
\text { ALDH3H1 }\end{array}$ & $A B A$ \\
\hline
\end{tabular}

Abbreviations: AUX:auxin; ET; ethylene; ABA: Abcisic acid; PM:plasma membrane; CW: cell wall; SCW: secondary cell wall; ER: endoplasmic reticulum; MVB/LE:microvesicular body/late endosome; TGN/EE:trans-golgy network/early endosome; VSR:vacuolar sorting receptors VN: vascular networks; PA: proanthocyanines; PIN; PIN formed auxin efflux carrier; RG:rhamnogalacturonan; XyG:xyloglucan. References supporting information in Table 4 are provided in Additional file 8: Table S7. 
Table 5 Genes discussed in the text correlated with sensitivity at harvest and during cold storage (cluster k-means 9)

\begin{tabular}{|c|c|c|c|c|c|c|c|c|c|}
\hline $\begin{array}{l}\text { Function specific } \\
\text { process }\end{array}$ & $\begin{array}{l}\text { Chillpeach } \\
\text { ID }\end{array}$ & $\begin{array}{l}\text { Unigene } \\
\text { annotation }\end{array}$ & Arab AGI & $\begin{array}{l}\text { Arab gene } \\
\text { symbol }\end{array}$ & $\begin{array}{l}\text { Hormone } \\
\text { signaling }\end{array}$ & $\begin{array}{l}\text { Sugar } \\
\text { signaling/ } \\
\text { partioning }\end{array}$ & $\begin{array}{l}\text { Hormone and } \\
\text { secondary } \\
\text { metabolite } \\
\text { biosynthesis } \\
\text { regulation }\end{array}$ & $\begin{array}{l}\text { Cell wall and } \\
\text { cytoesqueleton } \\
\text { related }\end{array}$ & Cell polarity \\
\hline
\end{tabular}

Cytoskeleton organization and biogenesis

Microtubule PPN077E06 Microtubute-

stability and associated protein

AT3G04630 WDL1

organization

$$
\text { associated protein }
$$

Negative regulator

of microtubule

structure and

stability

\section{Protein degradation}

Ubiquitin ligase PPN032H05 Cullin

E3 complex/

$\begin{array}{rll}\text { AT4G02570 } & \text { AXR6/ } & \text { AUX nuclear } \\ \text { CUL1 } & \text { signaling }\end{array}$

RNA transcription regulation

MYB-family PPN055C11

Sucrose responsive
element binding
protein

AT5G67300 MYBR1/

MYB44

$A B A, A \cup X, E T$

Sucrose

responsive

element

binding protein

Signal transduction pathway

G-protein coupled PPN065B10 Guanine nucleotide

$\begin{array}{ll}\text { receptor protein } & \text { binding protein } \\ \text { signaling } & \text { (G-protein), alph }\end{array}$

pathway/G

(G-protein), alpha

protein complex

subunit family protein

Phosphorylation PP1009F07 Trichoderma-induced

cascades/MAPK

protein kinase

\section{AT3G45640 MPK3}

Positive

regulation

of ACS type I

Phosphorylation PPN071C11 protein kinase family

cascades/MAPKKK protein/ankyrin

repeat family protein

Phosphorylation PPN014G07 Serine/threonine-

cascades/PP2A

$$
\begin{aligned}
& \text { protein } \\
& \text { phosphatase 2A } \\
& \text { regulatory subunit A } \\
& \text { beta isoform }
\end{aligned}
$$

$\begin{array}{lll}\text { AT1G14000 VIK } & \begin{array}{l}\text { AUX and BR } \\ \text { signaling }\end{array} \\ & & \begin{array}{l}\text { Regulates PIN } \\ \text { AT3G25800 PDF1/lular } \\ \text { PP2AA2 }\end{array} \\ & \text { distribution }\end{array}$

\section{Sugar
sensitivity}

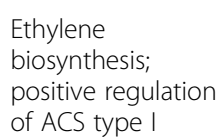

Sugar

partioning

and homeostasis

positive regulation

Pectin induced

VN formation

regulation 
Table 5 Genes discussed in the text correlated with sensitivity at harvest and during cold storage (cluster k-means 9) (Continued)

Trafficking machinery and membrane dynamics

CME;Vesicle coat/ PP1003H08 Putative Clathrin coat

clathrin coated

assembly protein AP50

vesicles

Fatty acid

biosyntheis

Glycerolipid

biosynthesis

Glycerolipid

metabolism

Phospholipid

biosynthesis

Trans-Golgi

network transpor

vesicle/COPI

vesicles

Transport

Carbohydrate

transport

Cl-channel

PP1003F09 Integral membrane protein,

PPN078A03 Cl-channel, voltage gated; IMP dehydrogenase related 1

$\mathrm{Na} / \mathrm{K}$ antiporter

PPN064A01 $\mathrm{Na}+/ \mathrm{H}+$ antiporter

Nitrate transport

Oligopepetide

transport

alpha subunit

synthase 1

phosphatase-related/ PAP2-related cytidylyltransferase NRT1-2

PPN005F03 Oligopeptide transporter
AT5G46630 AP2M

Regulates cellular

AUX levels by

controlling the

abundance and

distribution of PIN

proteins at the PM

AT2G38040 CAC3

PPN008G03 Digalactosyldiacylglycerol AT3G11670 DGD1

AT3G50920 LPPEPSILON

AT2G38670 PECT

AT5G13300 VAN3/SFC

required for either normal PIN1

cycling or for

PID-directed efflux

machinery

relocation

AT1G75220 ERDL6

AT5G33280 CLCG

AT2G01980 SOS1

AT1G18880 NRT1.9

PPN064F08 POT family, putative
Regulates cellulose Cell polarity

synthesis controlling regulation

the abundance and

distribution of active

CESA complexes at

the $P M$

Fatty acid

biosynthesis

Digalactosyl

diacylglycerol

biosynthesis

Polar targeting of

proteins to the PM;

Lipid microdomains

Diacylglycerol

Phosphoethanolamine

biosynthesis

Polar targeting of

proteins to the PM;

Lipid microdomain

Regulates formation

of plant VN regulation 
Table 5 Genes discussed in the text correlated with sensitivity at harvest and during cold storage (cluster k-means 9) (Continued)

\begin{tabular}{|c|c|c|c|c|c|}
\hline $\begin{array}{l}\text { Unknown } \\
\text { transporter }\end{array}$ & PPN066F09 & $\begin{array}{l}\text { Putative integral } \\
\text { membrane protein }\end{array}$ & AT5G19980 GONST4 & $\begin{array}{l}\text { Sugar partioning } \\
\text { and homeostasis }\end{array}$ & $\begin{array}{l}\text { Is probably involved } \\
\text { in the provision } \\
\text { of GDP- sugars into } \\
\text { the Golgi for CW } \\
\text { polysaccharide } \\
\text { synthesis such as } \\
\text { RG-II and XyG }\end{array}$ \\
\hline
\end{tabular}

\section{Unknown function}

$\begin{array}{lll}\begin{array}{l}\text { Unknown } \\ \text { interferon protein }\end{array} & \text { PPN065A05 } & \begin{array}{l}\text { Interferon-related } \\ \text { developmental } \\ \text { regulator family } \\ \text { protein }\end{array}\end{array}$

AT1G27760 SAT32

ABA

Unkown Zinc PP1003D02 Ubiquitin ligase

finger RING-like

AT3G23280 XBAT35

ET regulation

Glucose

Abbreviations: AUX:auxin; ET; ethylene; ABA: Abcisic acid; PM:plasma membrane;CW: cell wall; SCW: secondary cell wall; ER: endoplasmic reticulum; MVB/LE:microvesicular body/late endosome; TGN/EE:trans-golgy

network/early endosome; VSR:vacuolar sorting receptors VN:vascular networks; $P A$ : proanthocyanines; PIN; PIN formed auxin efflux carrier; RG:rhamnogalacturonan; XyG:xyloglucan.

References supporting information in Table 5 are provided in Additional file 8: Table 57. 
fruit. In addition, an important function of the TOR pathway is the regulation of mitochondrial activity and, hence, the production of ROS in animals [63] and in plants [61]. Thus, we suggest that while auxin changes are probably mainly related to cell wall in sensitive fruit, cytoplasmic auxin in tolerant fruit may be related to the maintenance of the translation machinery and the control of ROS.

\section{Ethylene is related to tolerance to cold storage}

Ethylene reduction has been correlated with WLT sensitivity $[27,28]$ and with the down regulation of some key cell wall activities associated to WLT development [8]. Zhou et al. [28] found that during prolonged cold storage, maintaining the ability of nectarine fruit to produce ethylene or adding exogenous ethylene to the storage atmosphere, prevented CI. Furthermore, correlating with ethylene production, the gene and protein expression of the ACO and ACS1were depleted during cold storage in fruit developing WLT during shelf life $[27,28]$. In agreement, we found that the most tolerant Od fruit have higher levels of both ACO and ACS (Additional file 3: Table S3). This is further supported by the qRT-PCR results (Figure 5B and Additional file 5: Table S4) and the positive correlation of the ACS1 with the tolerance degree in individual lines from the Pop-DG population (Additional file 7: Table S6 and [17]). Moreover, genes related to metabolism of the ethylene precursor methionine (salvage pathways and Yang cycle) and cyanide detoxification were in cluster k-means 5 (Table 3; Additional file 6: Table S5). It has been proposed that high rates of ethylene biosynthesis in climacteric fruit are supported by recycling of the ethylene precursor methionine via the Yang cycle [64] and by having an active system for handling cyanide, a byproduct of ethylene biosynthesis [65].

In addition several ethylene biosynthesis regulators and signaling elements were also differentially expressed between sensitive and tolerant fruit and their expression correlated with tolerance/sensitivity (Tables 2, 3, 4 and 5). EIN2 (ETHYLENE INSENSITIVE2) has been previously reported during cold storage in peach fruit [66] and it has been associated with cold sensitivity in Arabidopsis [67] and peach [17]. Both EIN2 and Ethyleneoverproduction protein 1 (ETO1) (in cluster k-means 1; Figure 6A) are implicated in the negative regulation of type II ACS. EIN2 participates in the negative feedback regulation of ethylene biosynthesis by affecting the expression of ACS type II at transcriptional level [68], while ETO1 inhibits the enzymatic activity of type II ACS and targets it for $26 \mathrm{~S}$ proteasome-mediated degradation [69]. In addition, in cluster k-means 2 (induced in CS and higher in sensitive fruit, Figure 6A) was VAS1 (reversal of vas3 phenotype; Table 2), recently identified as a cross-regulatory point controlling the flow through the auxin and ethylene biosynthetic pathways in response to shade [70]. VAS1 prevents over-accumulation of ethylene and auxin, thus preventing an exaggerated response to this environmental signal and vas1 mutants accumulate ACC and auxins.

Furthermore, associated with high tolerance to cold (cluster k-means 8, Figure 6A) were the orthologs of the ethylene receptor EIN4 (ethylene insensitive 4) and RAN1, a P-type ATPase copper transporter that delivers the copper ion to the receptors and is required for both ethylene binding and the receptor functionality (Table 3). In Arabidopsis, EIN4 plays a positive role during cold acclimation in Arabidopsis [67], which coincides with their high expression in tolerant Od fruit (Additional file 6: Table S5). However, although EIN2 and EIN4 seem to play a similar role in cold acclimation in peach fruit and Arabidopsis, high levels of ethylene enhance tolerance to $\mathrm{CI}$ in peach while having a negative effect on Arabidopsis [67]. This difference may be explained by the different organs considered (fruits and leaves) and developmental processes. A lack of ethylene production during cold storage affects normal fruit ripening and leads to WLT [28].

\section{Sugar homeostasis and hormone crosstalk: auxin, ethylene, ABA}

All three clusters (k-means 1, 2 and 9) associated to CI sensitivity were enriched in transport elements (Figure 6B). Besides the auxin transporters described above, these genes are rich in carbohydrate transporters and in oligopeptide/ metal ion transporters (Tables 2, 4 and 5; Additional file 3: Table S3). This suggests that nutrient reallocation could play a role in the cell wall remodeling and metabolic changes happening in sensitive fruit. This may be the case of golgi nucleotide sugar transporter GONST4 (cluster kmeans 9, Figure 5A), which is involved in the provision of GDP-fucose and GDP-1- galactose sugars into the Golgi for cell wall polysaccharide synthesis such as rhamnogalacturonan II and xyloglucan (Table 5), and ERDL6 (Early Responsive to Dehydration-Like 6) which functions as a vacuole glucose exporter (Table 5). Likewise, these transporters can also contribute to the sensitive character of peach fruit. Plants overexpressing ERDL6 or the sugar beet (Beta vulgaris) homolog BvIMP (Integral Membrane Protein) accumulated lower glucose and fructose in the vacuole than wild type and had reduced tolerance to cold [71].

In addition, the effect of cold on transporters can also reflect the stresses imposed to the fruit (cold, darkness and detachment), that may limit nutrient availability. It is described that in chilling sensitive peaches, glucose and fructose content increases during cold storage, while sucrose diminishes [72]. Emerging data indicate that sugar-derived signaling systems, including trehalose-6 phosphate (T6P), sucrose non-fermenting related kinase-1 (SnRK), and the TOR kinase complex also play important roles in regulating plant development through modulating nutrient and 
energy signaling and metabolic processes, especially under abiotic stresses where sugar availability is low (reviewed in [73]). Among signaling elements highly expressed in sensitive fruit were genes encoding for orthologs of several SnRKs of the three described groups SnRK1 (AKIN beta and aKING1, in clusters k-means 1 and 2), SnRK2 (SnRK2 OTS1/ SNRK2-6 and SNRK2.8, in cluster k-means 2) and SnRK3 (CIPK 10 and CIPK6; cluster k-means 1; Tables 2 and 4). Most of these genes have previously been associated to the chilling sensitive phenotype in peach [17]. Limited sucrose availability, osmotic stress and abscisic acid (ABA) activate the activity and the expression of SnRKs [74], which act as inhibitors of gene expression involved in different biosynthetic pathways [75]. The SnRK1 complex plays a central role in nutrient, darkness and stress [76]. Thus, it is likely that sucrose depletion by cold together with fruit detachment [72] enhances the expression of these genes. Furthermore, and in agreement with our results, the SnRK1 complex may play a role opposite to the one played by the TOR pathway in sensing energy [77] that promotes energy-consuming related cellular processes, such as mRNA translation when sucrose levels are high [77].

\section{Vesicle trafficking, membrane dynamics and cytoskeleton} organization related to WLT at a pre-symptomatic stage Our results indicate that differences in the expression levels of genes related to intracellular trafficking, cytoskeleton and lipid metabolism before and during cold storage (Tables 2, 3, 4 and 5 and Additional file 6: Table S5) could be related to the sensitivity or tolerance to $\mathrm{CI}$ in both a preformed (k-means 5; Figure 6A) and induced mechanism (k-means 2 and 9; Figure 6A). Similarly to other plants, this indicates that differences in membrane composition $[78,79]$, cytoskeleton stability [80] and polar transport of proteins $[81,82]$ participate in the response of peach fruit during cold. Differences in the expression of these genes could have a key role in the molecular phenotypes associated to the tolerance and sensitivity by regulating processes such as cell wall biosynthesis modifications and auxin distribution. Gonzalez Agüero et al. [83] suggested that alterations in the abundance of the endomembrane system components could have an important role in the development of WLT during cold and during shelf life by modifying the flow of polysaccharides and proteins to the cell wall. Furthermore, cytoskeleton $[84,85]$ and lipid composition of membranes $[86,87]$ are essential for, among other functions, polar distribution of membrane proteins, such as cell wall biosynthesis enzymes and auxin transporters.

\section{Gene expression related to sensitivity to $\mathrm{FB}$ and $\mathrm{FBL}$ at a pre-symptomatic stage}

$\mathrm{Hz}$ was the only fruit that developed FBL and FB during the storage period. Although the analysis using the four fruit types is biased for WLT, the comparison of pools and $\mathrm{Hz}-\mathrm{Od}$ experiments has identified a group of genes (k-means 11; Figure 6A) that only respond to cold in $\mathrm{Hz}$ fruit, and thus are good candidates to be related with $\mathrm{Hz}$ phenotype. This cluster is enriched in genes involved in the production of acetaldehyde and pyruvate metabolism (Figure 6B; Table 4). Further the same genes were identified as highly expressed in $\mathrm{Hz}$ compared to Od (Additional file 3: Table S3). Thus, acetaldehyde production could be related to the FBL and FB. FB is generally thought to be due to the action of polyphenol oxidase [9]. However, discoloration can also occur by non-enzymatic reactions through metal-polyphenol complexes [88]. This browning mechanism could be induced by chilling in $\mathrm{Hz}$ fruit. $\mathrm{Hz}$ fruit contained relatively high levels of expression of metal transport genes in comparison to Od and pools (Additional file 3: Tables S3 and Additional file 6: Table S5), which indicates a mobilization of metal ions associated to FB. Furthermore, high levels of PpLDOX correlated to BR sensitivity $[36,49]$ and the results presented here indicate that $\mathrm{Hz}$ fruit have relatively high levels of expression of genes related to proanthocyanin monomer biosynthesis (Table 3). The combination of these two factors (i.e., high expression of both proanthocyanin and metal mobilization genes) with high expression of acetaldehyde production genes may increase the propensity of the fruit to $\mathrm{FB}$ when moved to shelf life. Lastly, among genes associated to the FB at a pre-symptomatic stage was an ortholog of glutamate decarboxylase (GAD5; Table 4). Glutamatade decarboxylase catalyzes the first and irreversible step of gamma aminobutyric acid (GABA; [89]). GABA has been shown to be a metabolic marker for core breakdown in pear [90]. These possible genes FB and FBL should be validated with additional cultivars.

\section{Conclusions}

Our previous work prompted us to propose that in sensitive fruit a cold response program is activated, that is associated with dehydration/osmotic stress (induced by trapping water in cell wall pectins) and regulated by auxin distribution, ABA, and ethylene [17]. The results presented here indicate that sugar partitioning and demand during cold storage may also play an important role in the tolerance/sensitive mechanism and the interplay between sugar, cell wall and these three hormones (confirmed by the large list of regulators and signaling elements involved in the crosstalk of these factors, may have a role in the sensitive character even before fruit are cold stored. Furthermore, we validated and expanded the knowledge of the changes occurring in CI sensitive or tolerant fruit, by providing strong evidence of their correlation to sensitivity in a greater range of sensitivity/ tolerance. This resulted in a variety of novel genes that provide targets on which further experimental analysis 
should focus. However, this is still a partial view and more actors may participate in the cold response to cold storage in peach fruit.

\section{Availability of supporting data}

The data sets supporting the results of this article are available in the the ArrayExpress database (www.ebi.ac. $\mathrm{uk} /$ arrayexpress) under accession number E-MTAB-2708.

\section{Additional files}

Additional file 1: Table S1. Gene-specific primers for qRT-PCR.

Additional file 2: Table S2. Raw data. 3277 Chillpeach probes that met the threshold for hybridization quality. Expression data correspond to lowess M Log Ratio.

Additional file 3: Table S3. Genes differentially expressed between 'Oded' and 'Hermoza' at harvest and during cold storage. In the Table there are the results for direct comparisons from the global analysis. The Table provides ID, the averaged lowess M Log Ratio and functional annotations.

Additional file 4: Figure S1. Unsupervised two-dimensional hierarchical clustering of genes differentially expressed between 'Oded' and 'Hermoza' at harvest and during cold storage. Data represent averaged lowess $\mathrm{M}$ log ratio for three replicates. Color represents fold change (red: up-regulated and green: down-regulated). : Harvest; CS1: cold storage of 1 week at $5^{\circ} \mathrm{C} ; \mathrm{CS} 2$ : cold storage of 2 weeks at $5^{\circ} \mathrm{C}$; Od: 'Oded' peach; Hz: 'Hermoza' peach.

Additional file 5: Table S4. RT-PCR gene expression values for representative genes and correlation with microarray data. Ten candidate genes were assayed by quantitative RT-PCR in fruits from $\mathrm{Od}$ and $\mathrm{Hz}$ at harvest and after 1 and 2 weeks of cold storage. For each gene this is shown $\mathrm{Od}$ and $\mathrm{Hz}$ values at harvest and the average gene expression pattern relative to harvest values in both expression platforms, microarray and qRT-PCR. The agreement between qRT-PCR and microarrays in expression profiles across samples is expressed as Pearson correlation coefficient.

Additional file 6: Table S5. Comparison of genes differentially expressed at one week of cold storage between 'Oded' and Hermoza and between pools of siblings form the Pop-DG population. Data from fruits from the Pop-DG population cold stored were obtained from Pons et al. [17].

Additional file 7: Table S6. Comparison with genes previously validated in pools and in individual lines from the Pop-DG population. Data from fruits from the Pop-DG population cold stored were obtained from Pons et al. [17]. The cluster derived from Figure 6A is shown and the expression pattern at harvest and after one week of cold storage in pools LS and S. Also indicated are the genes validated in individual lines and pools.

Additional file 8: Table S7. Genes and references supporting information in Tables 2, 3, 4 and 5 .

\section{Abbreviations}

Cl: Chilling injury; FB: Flesh browning; FBL: Flesh reddening/bleeding; WLT: Woolliness/mealiness; Hz: Hermoza; Od: Oded; qRT-PCR: quantitative real-time PCR; ROS: Reactive oxygen species; M: Mature stage; SL: Shelf life; CS: Cold storage; S: high sensitive pool of siblings from the Pop-DG population; LS: Low sensitive pool of siblings from the Pop-DG population.

\section{Competing interests}

The authors declare that they have no competing interests.

\section{Authors' contributions}

$A D, C P P$ and $C M l$ performed the transcriptomics experiment and primary data analysis. HF and VS conducted the ROSMETER analysis. CPP carried out bioinformatics analysis. CPP, SL, AD, AG wrote the manuscript. All authors read and approved the final manuscript.

\section{Acknowledgments}

This research was funded by US-Israel Binational Agriculture Research and Development Fund (BARD) Grant no. US-4027-07. We thank the European Science Foundation for Short Term Scientific Mission grants to A. Dagar (COST Action 924, reference codes COST-STSM-924-04254 and Quality Fruit COST FA1106 for networking.

\section{Author details}

'Department of Postharvest Science of Fresh Produce, Agricultural Research Organization, Volcani Center, P.O. Box 6, Bet Dagan 50250, Israel. ${ }^{2}$ Instituto de Biología Molecular y Celular de Plantas, CSIC-Universidad Politecnica de Valencia, E-48022, Valencia, Spain. ${ }^{3}$ Plant Sciences Department, University of California Davis, 1 Shields Ave, Davis, CA 95616, USA.

Received: 24 July 2014 Accepted: 24 February 2015

Published online: 26 March 2015

\section{References}

1. Crisosto C, Mitchell F, Ju Z. Susceptibility to chilling injury of peach, nectarine, and plum cultivars grown in California. Hort Sci. 1999;34:1116-8.

2. Lurie $S$, Crisosto $C$. Chilling injury in peach and nectarine. Postharvest Biol Technol. 2005;37:195-208.

3. Crisosto C, Mitchell F, Johnson S. Factors in fresh market stone fruit quality. Postharvest News Inform. 1995;6(2):17-21.

4. Dawson DM, Melton LD, Watkins CB. Cell wall changes in nectarines (Prunus persica): solubilization and depolymerization of pectic and neutral polymers during ripening and in mealy fruit. Plant Physiol. 1992;100(3):1203-10.

5. Zhou H, Sonego L, Khalchitski A, Ben Arie R, Lers A, Lurie A. Cell wall enzymes and cell wall changes in 'Flavortop' nectarines: mRNA abundance, enzyme activity, and changes in pectic and neutral polymers during ripening and in woolly fruit. J Am Soc Hort Sci. 2000;125:630-7.

6. Jarvis MC, Briggs SPH, Knox JP. Intercellular adhesion and cell separation in plants. Plant Cell Environ. 2003:26(7):977-89.

7. Zhou H, Ben-Arie R, Lurie S. Pectin esterase, polygalacturonase and gel formation in peach pectin fractions. Phytochemistry. 2000;55(3):191-5.

8. Brummell DA, Dal Cin V, Lurie S, Crisosto CH, Labavitch JM. Cell wall metabolism during the development of chilling injury in cold-stored peach fruit: association of mealiness with arrested disassembly of cell wall pectins. J Exp Bot. 2004;55(405):2041-52.

9. Kader AA, Chordas A. Evaluating the browning potential of peaches. Calif Agric. 1984;38:14-5.

10. Cevallos-Casals BA, Byrne D, Okie WR, Cisneros-Zevallos L. Selecting new peach and plum genotypes rich in phenolic compounds and enhanced functional properties. Food Chem. 2006;96(2):273-80.

11. Rojas G, Méndez MA, Muñoz C, Lemus G, Hinrichsen P. Identification of a minimal microsatellite marker panel for the fingerprinting of peach and nectarine cultivars. Electron J Biotechnol. 2008;11:4-5.

12. Scorza R, Sherman WB, Lightner GW. Inbreeding and co-ancestry of low chill short fruit development period freestone peaches and nectarines produced by the University of Florida breeding program. Fruit Varieties $J$ 1988:43:79-85.

13. Brooks R, Olmo HP. Register of New Fruit and Nut Varieties, 2nd edition edn: Univ of California Press; 1972

14. Okie WR, Service USAR. Handbook of peach and nectarine varieties: performance in the southeastern United States and index of names: U.S. Dept. of Agriculture, Agricultural Research Service; 1998

15. Martínez-García P, Peace C, Parfitt D, Ogundiwin E, Fresnedo-Ramírez J, Dandekar A, et al. Influence of year and genetic factors on chilling injury susceptibility in peach (Prunus persica (L.) Batsch). Euphytica. 2012;185(2):267-80.

16. Ogundiwin E, Martí C, Forment J, Pons C, Granell A, Gradziel T, et al. Development of ChillPeach genomic tools and identification of cold-responsive genes in peach fruit. Plant Mol Biol. 2008;68(4-5):379-97.

17. Pons C, Martí C, Forment J, Crisosto CH, Dandekar AM, Granell A. A Bulk Segregant Gene Expression Analysis of a Peach Population Reveals Components of the Underlying Mechanism of the Fruit Cold Response. PLoS ONE. 2014;9(3):e90706. 
18. Rosenwasser S, Fluhr R, Joshi JR, Leviatan N, Sela N, Hetzroni A, et al. ROSMETER: A Bioinformatic Tool for the Identification of Transcriptomic Imprints Related to Reactive Oxygen Species Type and Origin Provides New Insights into Stress Responses. Plant Physiol. 2013;163(2):1071-83.

19. Kader AA, Mitchell FG. Maturity and quality. In: James H. LaRue RSJ, vol. Publication No. 3331, editor. Peaches, Plums, and Nectarines: Growing and Handling for Fresh Market. Oakland, Calif: Cooperative Extension, University of California, Division of Agriculture and Natural Resources; 1989. p. 191-6.

20. Dagar A, Friedman H, Lurie S. Thaumatin-like proteins and their possible role in protection against chilling injury in peach fruit. Postharvest Biol Technol. 2010;57(2):77-85

21. Lill RE, Van Der Mespel GJ. A method for measuring the juice content of mealy nectarines. Sci Hortic. 1988;36(3-4):267-71.

22. Tusher VG, Tibshirani R, Chu G. Significance analysis of microarrays applied to the ionizing radiation response. Proc Natl Acad Sci. 2001;98(9):5116-21.

23. Pavlidis $P$, Noble WS. Matrix2png: a utility for visualizing matrix data. Bioinformatics. 2003;1-9(2):295-6.

24. Dagar A, Pons Puig C, Marti Ibanez C, Ziliotto F, Bonghi CH, Crisosto C, et al. Comparative transcript profiling of a peach and its nectarine mutant at harvest reveals differences in gene expression related to storability. Tree Genet Genomes. 2013;9(1):223-35.

25. Doherty CJ, Van Buskirk HA, Myers SJ, Thomashow MF. Roles for Arabidopsis CAMTA transcription factors in cold-regulated gene expression and freezing tolerance. Plant Cell. 2009;21(3):972-84.

26. Gilmour S, Zarka D, Stockinger E, Salazar M, Houghton J, Thomashow M. Low temperature regulation of the Arabidopsis CBF family of AP2 transcriptional activators as an early step in cold-induced COR gene expression. Plant J. 1998;16(4):433-42.

27. Dong L, Zhou H-W, Sonego L, Lers A, Lurie S. Ethylene involvement in the cold storage disorder of 'Flavortop' nectarine. Postharvest Biol Technol. 2001;23(2):105-15.

28. Zhou H-W, Dong L, Ben-Arie R, Lurie S. The role of ethylene in the prevention of chilling injury in nectarines. J Plant Physiol. 2001;158(1):55-61.

29. Kilian J, Whitehead D, Horak J, Wanke D, Weinl S, Batistic O, et al. The AtGenExpress global stress expression data set: protocols, evaluation and model data analysis of UV-B light, drought and cold stress responses. Plant J. 2007;50(2):347-63.

30. Giraldo E, Díaz A, Corral JM, García A. Applicability of 2-DE to assess differences in the protein profile between cold storage and not cold storage in nectarine fruits. J Proteome. 2012;75(18):5774-82.

31. Obenland D, Vensel W, Hurkman li W. Alterations in protein expression associated with the development of mealiness in peaches. J Hortic Sci Biotechnol. 2008;83(1):85-93.

32. Vizoso P, Meisel L, Tittarelli A, Latorre M, Saba J, Caroca R, et al. Comparative EST transcript profiling of peach fruits under different post-harvest conditions reveals candidate genes associated with peach fruit quality. BMC Genomics. 2009;10(1):423.

33. Hannah M, Heyer A, Hincha D. A Global Survey of Gene Regulation during Cold Acclimation in Arabidopsis thaliana. PLoS Genet. 2005;1 (2):e26.

34. Walia H, Wilson C, Condamine P, Liu X, Ismail AM, Zeng L, et al. Comparative Transcriptional Profiling of Two Contrasting Rice Genotypes under Salinity Stress during the Vegetative Growth Stage. Plant Physiol. 2005;139(2):822-35.

35. Lurie S, Zhou H-W, Lers A, Sonego L, Alexandrov S, Shomer I. Study of pectin esterase and changes in pectin methylation during normal and abnormal peach ripening. Physiol Plant. 2003;119(2):287-94.

36. Peace C, Crisosto C, Gradziel T. Endopolygalacturonase: A candidate gene for Freestone and Melting flesh in peach. Mol Breed. 2005;16(1):21-31.

37. Luza JG, van Gorsel R, Polito VS, Kader AA. Chilling Injury in Peaches: A Cytochemical and Ultrastructural Cell Wall Study. J Am Soc Hortic Sci. 1992;117(1):114-8

38. Masia A, Zanchin A, Rascio N, Ramina A. Some Biochemical and Ultrastructural Aspects of Peach Fruit Development. J Am Soc Hortic Sci. 1992;117(5):808-15.

39. Dean GH, Zheng H, Tewari J, Huang J, Young DS, Hwang YT, et al. The Arabidopsis MUM2 Gene Encodes a $\beta$-Galactosidase Required for the Production of Seed Coat Mucilage with Correct Hydration Properties. Plant Cell Online. 2007;19(12):4007-21.

40. Johnson CS, Kolevski B, Smyth DR. TRANSPARENT TESTA GLABRA2, a Trichome and Seed Coat Development Gene of Arabidopsis, Encodes a WRKY Transcription Factor. Plant Cell Online. 2002;14(6):1359-75.
41. Karssen CM, der Swan DLC B-v, Breekland AE, Koornneef M. Induction of dormancy during seed development by endogenous abscisic acid: studies on abscisic acid deficient genotypes of Arabidopsis thaliana (L.) Heynh. Planta. 1983;157(2):158-65.

42. Bui M, Lim N, Sijacic P, Liu Z. LEUNIG_HOMOLOG and LEUNIG Regulate Seed Mucilage Extrusion in ArabidopsisF. J Integr Plant Biol. 201 1;53(5):399-408.

43. Hussey S, Mizrachi E, Spokevicius A, Bossinger G, Berger D, Myburg A. SND2, a NAC transcription factor gene, regulates genes involved in secondary cell wall development in Arabidopsis fibres and increases fibre cell area in Eucalyptus. BMC Plant Biol. 2011;11(1):173.

44. Jin H, Cominelli E, Bailey P, Parr A, Mehrtens F, Jones J, et al. Transcriptional repression by AtMYB4 controls production of UV-protecting sunscreens in Arabidopsis. EMBO J. 2000;19(22):6150-61.

45. Romera-Branchat M, Ripoll JJ, Yanofsky MF, Pelaz S. The WOX13 homeobox gene promotes replum formation in the Arabidopsis thaliana fruit. Plant J. 2013;73(1):37-49.

46. Itkin M, Seybold H, Breitel D, Rogachev I, Meir S, Aharoni A. TOMATO AGAMOUS-LIKE 1 is a component of the fruit ripening regulatory network. Plant J. 2009;60(6):1081-95.

47. Bemer M, Karlova R, Ballester AR, Tikunov YM, Bovy AG, Wolters-Arts M, et al. The Tomato FRUITFULL Homologs TDR4/FUL1 and MBP7/FUL2 Regulate Ethylene-Independent Aspects of Fruit Ripening. Plant Cell Online. 2012;24(11):4437-51

48. Jaakola L, Poole M, Jones MO, Kämäräinen-Karppinen T, Koskimäki JJ, Hohtola A, et al. A SQUAMOSA MADS Box Gene Involved in the Regulation of Anthocyanin Accumulation in Bilberry Fruits. Plant Physiol. 2010;153(4):1619-29.

49. Ogundiwin EA, Peace CP, Nicolet CM, Rashbrook VK, Gradziel TM, Bliss FA, et al. Leucoanthocyanidin dioxygenase gene (PpLDOX): a potential functional marker for cold storage browning in peach. Tree Genetics Genomes. 2008;4(3):543-54.

50. Baxter IR, Young JC, Armstrong G, Foster N, Bogenschutz N, Cordova T, et al. A plasma membrane $\mathrm{H}+-$ ATPase is required for the formation of proanthocyanidins in the seed coat endothelium of Arabidopsis thaliana. Proc Natl Acad Sci U S A. 2005;102(7):2649-54.

51. Cheng GW, Crisosto $\mathrm{CH}$. Browning Potential, Phenolic Composition, and Polyphenoloxidase Activity of Buffer Extracts of Peach and Nectarine Skin Tissue. J Am Soc Hortic Sci. 1995;120(5):835-8.

52. Wang Y-S, Tian S-P, Xu Y. Effects of high oxygen concentration on pro- and anti-oxidant enzymes in peach fruits during postharvest periods. Food Chem. 2005;91(1):99-104.

53. Sevillano L, Sanchez-Ballesta MT, Romojaro F, Flores FB. Physiological, hormonal and molecular mechanisms regulating chilling injury in horticultural species. Postharvest technologies applied to reduce its impact. J Sci Food Agric. 2009;89(4):555-73.

54. Provart NJ, Gil P, Chen W, Han B, Chang HS, Wang X, et al. Gene expression phenotypes of Arabidopsis associated with sensitivity to low temperatures. Plant Physiol. 2003;132(2):893-906.

55. Prasad T, Anderson M, Stewart C. Acclimation, Hydrogen Peroxide, and Abscisic Acid Protect Mitochondria against Irreversible Chilling Injury in Maize Seedlings. Plant Physiol. 1994;105(2):619-27.

56. Mhamdi A, Queval G, Chaouch S, Vanderauwera S, Van Breusegem F, Noctor G. Catalase function in plants: a focus on Arabidopsis mutants as stress-mimic models. J Exp Bot. 2010;61(15):4197-220.

57. Ulmasov T, Murfett J, Hagen G, Guilfoyle TJ. Aux/IAA proteins repress expression of reporter genes containing natural and highly active synthetic auxin response elements. Plant Cell Online. 1997;9(11):1963-71.

58. Schepetilnikov M, Dimitrova M, Mancera E, Martínez AG, Keller M, Ryabova LA. TOR and S6K1 promote translation reinitiation of UORF containing mRNAs via phosphorylation of elF3h. EMBO J. 2013;32(8):1087-102.

59. Xiong Y, Sheen J. The Role of Target of Rapamycin Signaling Networks in Plant Growth and Metabolism. Plant Physiol. 2014;164(2):499-512.

60. Murray JAH, Jones A, Godin C, Traas J. Systems Analysis of Shoot Apical Meristem Growth and Development: Integrating Hormonal and Mechanical Signaling. Plant Cell Online. 2012;24(10):3907-19.

61. Leiber R-M, John F, Verhertbruggen Y, Diet A, Knox JP, Ringli C. The TOR Pathway Modulates the Structure of Cell Walls in Arabidopsis. Plant Cell Online. 2010;22(6):1898-908.

62. Garcia-Hernandez M, Davies E, Baskin Tl, Staswick PE. Association of Plant p40 Protein with Ribosomes Is Enhanced When Polyribosomes Form during Periods of Active Tissue Growth. Plant Physiol. 1996;111(2):559-68. 
63. Cunningham JT, Rodgers JT, Arlow DH, Vazquez F, Mootha VK, Puigserver $P$. mTOR controls mitochondrial oxidative function through a YY1-PGC-1[agr] transcriptional complex. Nature. 2007;450(7170):736-40

64. Baur AH, Yang SF. Methionine metabolism in apple tissue in relation to ethylene biosynthesis. Phytochemistry. 1972;11(11):3207-14.

65. Peiser GD, Wang T-T, Hoffman NE, Yang SF, Liu H-W, Walsh CT. Formation of cyanide from carbon 1 of 1-aminocyclopropane-1-carboxylic acid during its conversion to ethylene. Proc Natl Acad Sci. 1984;81(10):3059-63.

66. Begheldo M, Manganaris GA, Bonghi C, Tonutti P. Different postharvest conditions modulate ripening and ethylene biosynthetic and signal transduction pathways in Stony Hard peaches. Postharvest Biol Technol. 2008;48(1):8-8.

67. Shi Y, Tian S, Hou L, Huang X, Zhang X, Guo H, et al. Ethylene signaling negatively regulates freezing tolerance by repressing expression of CBF and type-A ARR genes in Arabidopsis. Plant Cell. 2012;24(6):2578-95.

68. Thain SC, Vandenbussche F, Laarhoven LJJ, Dowson-Day MJ, Wang Z-Y, Tobin EM, et al. Circadian Rhythms of Ethylene Emission in Arabidopsis. Plant Physiol. 2004;136(3):3751-61.

69. Wang KLC, Yoshida H, Lurin C, Ecker JR. Regulation of ethylene gas biosynthesis by the Arabidopsis ETO1 protein. Nature. 2004;428(6986):945-50.

70. Zheng Z, Guo Y, Novák O, Dai X, Zhao Y, Ljung K, et al. Coordination of auxin and ethylene biosynthesis by the aminotransferase VAS1. Nat Chem Biol. 2013;9(4):244-6.

71. Poschet G, Hannich B, Raab S, Jungkunz I, Klemens PAW, Krueger S, et al. A Novel Arabidopsis Vacuolar Glucose Exporter is involved in cellular Sugar Homeostasis and affects Composition of Seed Storage Compounds. Plant Physiol. 2011;157(4):1664-76.

72. Wang K, Shao X, Gong Y, Zhu Y, Wang H, Zhang X, et al. The metabolism of soluble carbohydrates related to chilling injury in peach fruit exposed to cold stress. Postharvest Biol Technol. 2013;86:53-61.

73. Liu Y-H, Offler CE, Ruan Y-L. Regulation of fruit and seed response to heat and drought by sugars as nutrients and signals. Frontiers Plant Sci. 2013:4:282.

74. Coello P, Hey SJ, Halford NG. The sucrose non-fermenting-1-related (SnRK) family of protein kinases: potential for manipulation to improve stress tolerance and increase yield. J Exp Bot. 2011;62(3):883-93.

75. Baena-González E, Sheen J. Convergent energy and stress signaling. Trends Plant Sci. 2008:13(9):474-82

76. Baena-González E. Energy Signaling in the Regulation of Gene Expression during Stress. Mol Plant. 2010;3(2):300-13.

77. Robaglia C, Thomas M, Meyer C. Sensing nutrient and energy status by SnRK1 and TOR kinases. Curr Opin Plant Biol. 2012;15(3):301-7.

78. Uemura M, Joseph RA, Steponkus PL. Cold Acclimation of Arabidopsis thaliana (Effect on Plasma Membrane Lipid Composition and Freeze-Induced Lesions). Plant Physiol. 1995;109(1):15-30.

79. Zhang C, Tian S. Crucial contribution of membrane lipids' unsaturation to acquisition of chilling-tolerance in peach fruit stored at $0^{\circ} \mathrm{C}$. Food $\mathrm{Chem}$. 2009;115(2):405-11.

80. Abdrakhamanova A, Wang QY, Khokhlova L, Nick P. Is Microtubule Disassembly a Trigger for Cold Acclimation? Plant Cell Physiol. 2003:44(7):676-86.

81. Baluška F, Hlavacka A, Šamaj J, Palme K, Robinson DG, Matoh T, et al. F-Actin-Dependent Endocytosis of Cell Wall Pectins in Meristematic Root Cells. Insights from Brefeldin A-Induced Compartments. Plant Physiology. 2002;130(1):422-31

82. Baluška F, Liners F, Hlavačka A, Schlicht M, Van Cutsem P, McCurdy DW, et al. Cell wall pectins and xyloglucans are internalized into dividing root cells and accumulate within cell plates during cytokinesis. Protoplasma. 2005:225(3-4):141-55.

83. Gonzalez-Aguero M, Pavez L, Ibanez F, Pacheco I, Campos-Vargas R, Meisel $L$, et al. Identification of woolliness response genes in peach fruit after post-harvest treatments. J Exp Bot. 2008;59(8):1973-86.

84. Bashline L, Lei L, Li S, Gu Y. Cell Wall, Cytoskeleton, and Cell Expansion in Higher Plants. Mol Plant. 2014:4:586-600

85. Dhonukshe P, Grigoriev I, Fischer R, Tominaga M, Robinson DG, Hašek J, et al. Auxin transport inhibitors impair vesicle motility and actin cytoskeleton dynamics in diverse eukaryotes. Proc Natl Acad Sci. 2008;105(11):4489-94.

86. Fischer U, Men S, Grebe M. Lipid function in plant cell polarity. Curr Opin Plant Biol. 2004:7(6):670-6.
87. Schrick K, Fujioka S, Takatsuto S, Stierhof Y-D, Stransky H, Yoshida S, et al. A link between sterol biosynthesis, the cell wall, and cellulose in Arabidopsis. Plant J. 2004;38(2):227-43.

88. Cheng GW, Crisosto CH. Iron-Polyphenol Complex Formation and Skin Discoloration in Peaches and Nectarines. J Am Soc Hortic Sci. 1997;122(1):95-9.

89. Bouché N, Fait A, Zik M, Fromm H. The root-specific glutamate decarboxylase (GAD1) is essential for sustaining GABA levels in Arabidopsis. Plant Mol Biol. 2004;55(3):315-25.

90. Pedreschi R, Franck C, Lammertyn J, Erban A, Kopka J, Hertog M, et al. Metabolic profiling of 'Conference' pears under low oxygen stress. Postharvest Biol Technol. 2009;51(2):123-30.

\section{Submit your next manuscript to BioMed Central and take full advantage of:}

- Convenient online submission

- Thorough peer review

- No space constraints or color figure charges

- Immediate publication on acceptance

- Inclusion in PubMed, CAS, Scopus and Google Scholar

- Research which is freely available for redistribution 